\title{
Distinguishing Radiation Pneumonitis from Local Tumour Recurrence Following SBRT for Lung Cancer
}

This article was published in the following Dove Press journal:

Reports in Medical Imaging

\section{Bernd Frerker \\ Guido Hildebrandt \\ Department of Radiation Oncology, University Hospital Rostock, Rostock, Germany}

\begin{abstract}
Radiation pneumonitis is one of the most common toxicities following SBRT for lung cancer. Although local control rates are good, a recurrent tumour is difficult to distinguish from radiation pneumonitis due to similar size and morphology. Therefore, early detection of a recurrent tumour is challenging, and moreover, it is crucial for affected patients, as early detection enables curative salvage therapy. Promising data exists to solve these challenges for late recurrences, for example, the analysis of high-risk CT features allows prediction of recurrence after 12 months. But particularly in cases of early recurrences and radiation pneumonitis, comprehensive data are lacking. Therefore, the aim of this study was to review the existing literature with special regard to radiological response assessment after stereotactic body radiotherapy and risk factors for predicting radiation pneumonitis or local recurrence.
\end{abstract}

Keywords: radiation pneumonitis, tumour recurrence, stereotactic body radiotherapy

\section{Plain Language Summary}

Radiation pneumonitis is one of the most common toxicities following stereotactic body radiotherapy (SBRT) for lung cancer. It appears within 6 months after SBRT and more than $50 \%$ of the patients have corresponding radiological findings, but they are usually asymptomatic. By contrast, local recurrence is less common as local control rates are good. However, distinguishing radiation pneumonitis from a recurrent tumour is challenging due to similar morphology and size. This study aimed to review the literature which investigated predictive factors concerning radiation pneumonitis and local tumour recurrence after SBRT. Indeed, we found promising data. For example, Mattonen and her team reported a computer-aided algorithm for predicting local recurrence within 6 months. Moran and colleagues developed a similar procedure for predicting radiation pneumonitis. Furthermore, the use of positron emission tomography (PET) is encouraging. Huang et al developed a follow-up algorithm for response-assessment after SBRT, in which a PET is recommended in some cases, and Dong et al demonstrated that patients with high metabolic activity (described as SUVmax) before treatment had a worse overall survival. Nevertheless, the interpretation of a PET-scan should be done carefully as there is no optimal SUVmax threshold for predicting local recurrence or radiation pneumonitis. Another approach is to analyse of dosimetric parameters before performing SBRT, and indeed, some parameters seem to be associated with radiation pneumonitis, but again no specific dose constraints are found yet. We found promising data in the literature, but the results are controversial, and a conclusion could not be drawn.

\section{Introduction}

Lung cancer is the leading cancer type worldwide with regard to the number of new cases and causes of death. ${ }^{1}$ The therapeutic options are surgery, radiosurgery, respectively, ablative (stereotactic) radiotherapy, conventional radiotherapy, chemotherapy or immunotherapy. The
Department of Radiation Oncology

University Hospital of Rostock, Südring 75,

Rostock 18059, Germany

Tel +4938I 4949001

Fax +493814949002

Email bernd.frerker@uni-rostock.de
Reports in Medical Imaging 2020:13 I-23

(c) 12020 Frerker and Hildebrandt. This work is published and licensed by Dove Medical Press Limited. The full terms of this license are available at https://www.dovepress cc) com/terms.php and incorporate the Creative Commons Attribution - Non Commercial (unported, v3.0) License (http://creativecommons.org glicenses/by-ncc/3.0). By accessing the work you herbby accept the Terms. Non-commercial uses of the work are permitted without any further permission from Dove Medical Press Limited, provided the work is properly attributed. For permission for commercial use of this work, please see paragraphs 4.2 and 5 of our Terms (https://www.dovepress.com/terms.php). 
therapeutic strategy depends on the histological type, tumour stage and the constitution of the patients. ${ }^{2}$ In cases of early staged lung cancer (T1-2N0M0), stereotactic body radiotherapy (SBRT) is now a standard treatment option ${ }^{3}$ for medically inoperable patients, ${ }^{4,5}$ and it is considered to be a safe technique with low rates of severe toxicity. ${ }^{6}$ A 3-year local control rate of approximately $>90 \%$ has been reported. ${ }^{7,8}$ Moreover, SBRT could be an option for oligometastatic patients with excellent local control rates and encouraging overall survival, ${ }^{9}$ and for operable patients as results are comparable to those from surgery. ${ }^{10,11}$

Radiological changes are commonly seen after SBRT. ${ }^{12}$ Compared to conventional fractionated radiotherapy (CRT), SBRT allows the delivery of high doses per fraction while sparing surrounding normal lung tissue. Using volumetric modulated arc therapy (VMAT, Figures 1 and 2) or intensitymodulated radiation therapy (IMRT, 3-8 fractions, Figure 3), a dose distribution highly conformal to the shape of the tumour (high-dose region) and step-down dose gradients at its boundary (low-dose region) can be achieved. ${ }^{13}$ Older techniques such as CRT are less conformal to the tumour. It is expected that radiological patterns of radiological changes on a computed tomography (CT) after SBRT are different from those after CRT. ${ }^{14}$ On the one hand, CT changes after CRT are limited to the irradiated lung and thus conform to the treatment ports, where a distinct boundary between the irradiated and non-irradiated lung can be seen. ${ }^{15}$ On the other hand, due to the more complex dose distribution of SBRT, with highly conformal high-dose region (surrounding the tumour) and large irregular low-dose region (surrounding normal lung tissue, Figures 4, 5, and 6), CT changes do not show distinct boundaries and typically conform to the shape of tumour (Figures 1, 2, and 3). ${ }^{15}$

As reported by Linda et al, ${ }^{15}$ the CT changes following SBRT can be divided into an early stage within 6 months (Table 1), mainly related to radiation pneumonitis (RP), and a late stage after 6 months, related to radiation fibrosis. Radiation pneumonitis is one of the most common toxicities after SBRT, ${ }^{16}$ up to $50-60 \%$ of the patients show acute radiological findings. ${ }^{17}$ Most patients usually are asymptomatic (grade $0-1$, Common Terminology Criteria of Adverse Events, CTCAE), and reported rates of symptomatic RP (CTCAE grade $2-4$ ) range from $9 \%$ to $28 \%{ }^{18}$

Although local control rates are good, one of the most challenging problem is the differentiation of those benign post-SBRT radiological findings from malign local recurrence. They appear as an increase in CT density, and RP might mimic a recurrence due to similar morphology and size $^{19}$ making the physicians' decision of salvage treatment options more difficult. Promising data exists to solve these challenges for late recurrences, for example, the analysis of high-risk CT features allows to predict recurrence after 12 months. ${ }^{20}$ But particularly in cases of early recurrences and RP, comprehensive data are lacking. Hence, we aimed to review the literature concerning early recurrence and radiation pneumonitis after SBRT for lung cancer.

\section{Methods}

\section{Literature Research}

We accomplished a comprehensive literature research using the PubMed Database for articles published between January 2006 and April 2019. The following keywords were utilised: Pneumonitis, lung injury, fibrosis, recurrence, relapse, local failure, CT changes, CT appearance, imaging changes, early changes, texture analysis, radiomics, predictive, prognostic and risk factor. These keywords were accompanied by SBRT, SABR and lung cancer. After excluding duplicates, a total of 1078 articles were found. These articles were screened by cross-reading titles and abstracts. Articles directly concerning pneumonitis, fibrosis and recurrence, respectively, predictive factors and imaging findings after SBRT were selected, resulting in about 180 articles for final analysis. Twenty additional studies were included by interest after screening lists of reference. In brief, the following aspects were found:

- general radiographical changes after SBRT

- impact of different treatment techniques

- computed tomography (CT) analysis to distinguish tumour recurrence and radiation pneumonitis

- positron emission tomography (PET) to distinguish tumour recurrence and radiation pneumonitis

- dosimetric factors to predict pneumonitis

- impact of patient-based risk factors

In this review, we report the results as a summary of the most promising data available in the literature we found.

\section{Patients and Creation of the Figures}

We retrospectively checked our patient database (from 2018 and 2019) and picked up 11 patients with radiological signs of radiation pneumonitis or tumour recurrence. They are illustrated in 10 figures. CT findings after SBRT are shown in Figures 1-7: Figures 1-3 show radiation pneumonitis after SBRT. Using a deformable image registration, we demonstrate that these findings are conformal to the high dose region. In 
A

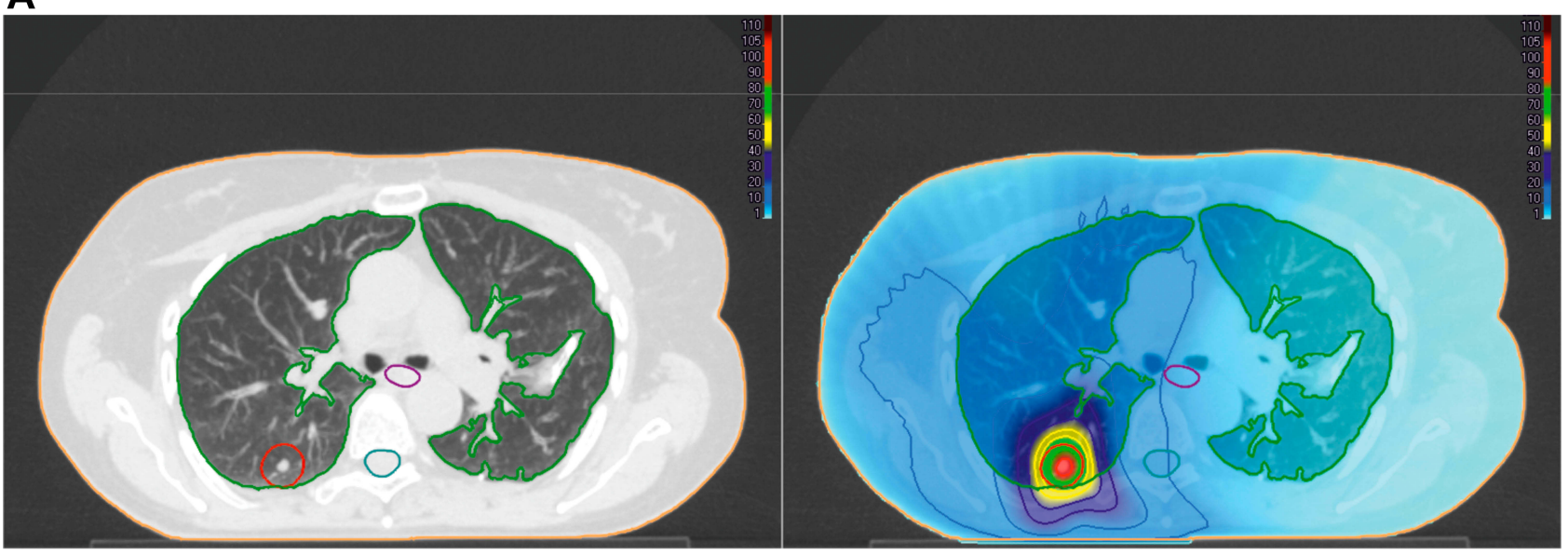

B

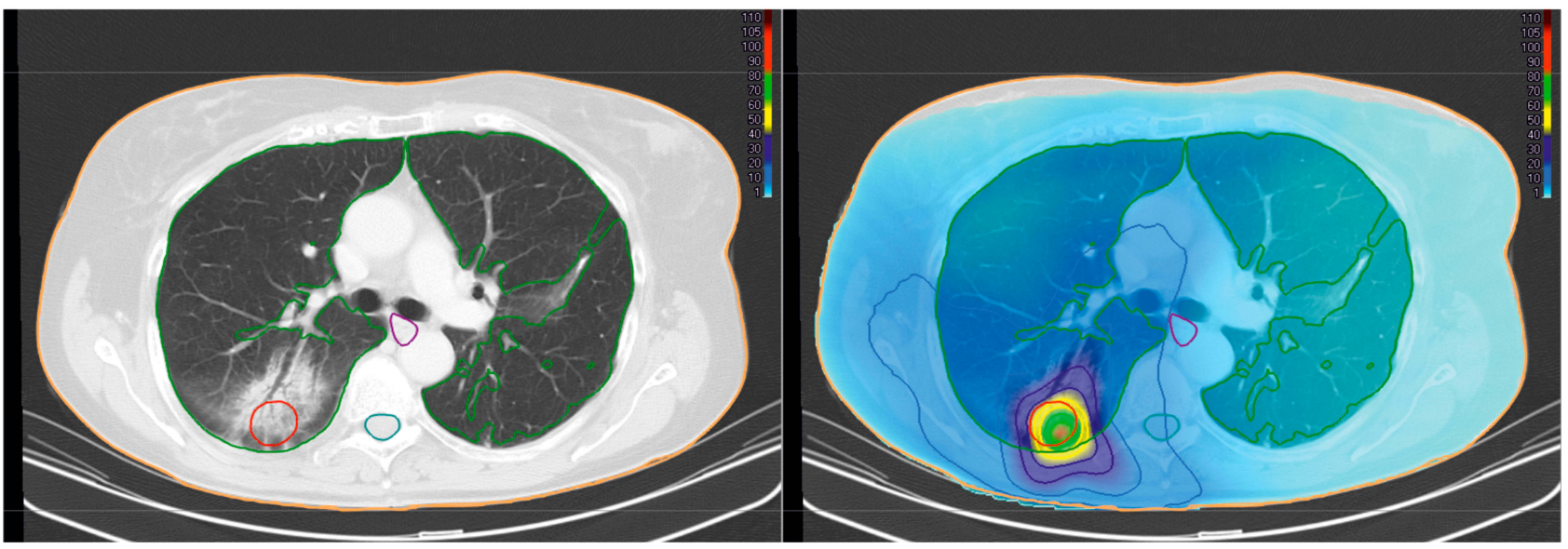

C

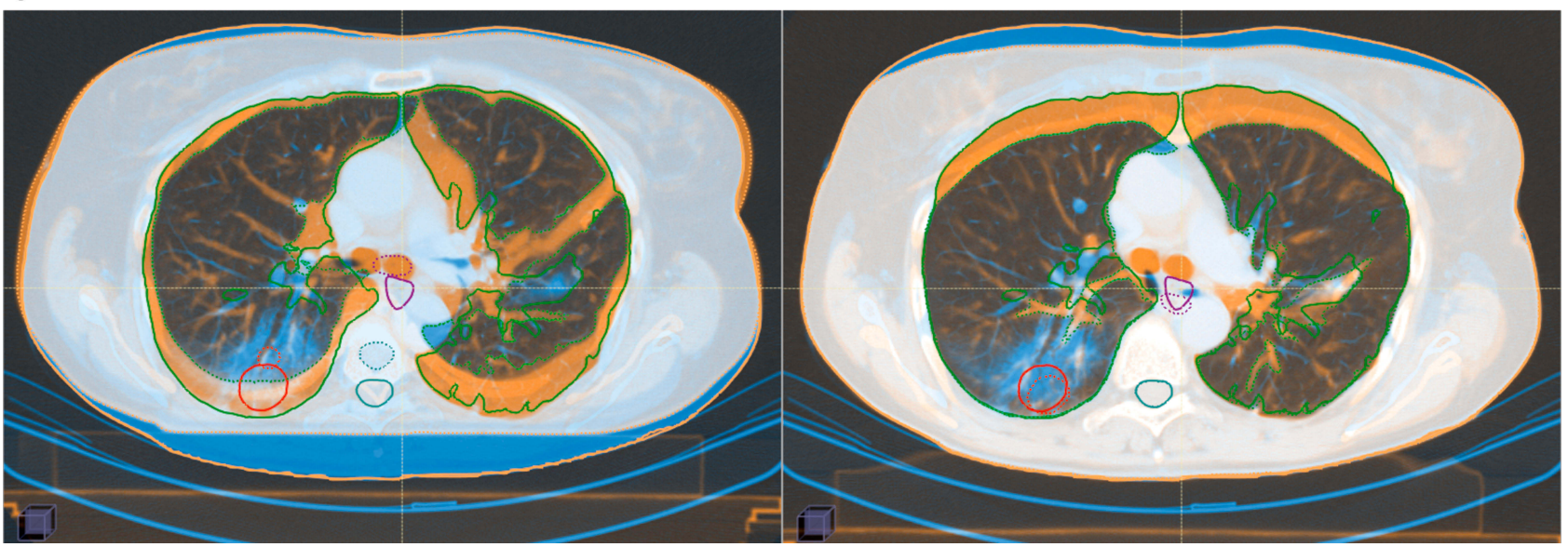

Figure I Radiation pneumonitis after SBRT. (A left): 74-year-old female patient treated with SBRT for lung metastasis of parathyroid carcinoma (within the red contour). Planning target volume (red contour) and organs at risk: Total lung (green), spinal cord (turquoise), oesophagus (violet). (A right): Treatment plan (VMAT-technology, I5 Gy in 3 fractions, total dose $45.0 \mathrm{~Gy}$ ): Isodose lines (\% of total dose) and the dose distribution, high-dose region surrounding the tumour (red, green), step down gradient (yellow, dark blue), and a large low-dose region highlighted in blue. (B left): Ground-glass opacities after SBRT, suspected radiation pneumonitis. (B right): A deformable image registration was used to correlate the lung changes on follow-up CT-scan with radiation dose distribution. The changes are conformal to the high- and mid-dose region. (C): A pre-treatment image (orange, dashed lines) and a follow-up image (blue, solid lines) were fused. A rigid image registration (left) cannot account for lung volume and tumour position changes on follow-up CT-scans. The images do not correlate with each other. The deformable image registration (right) is more accurate than the rigid registration and the images correlate well with each other.

Abbreviation: VMAT, volumetric modulated arc therapy. 


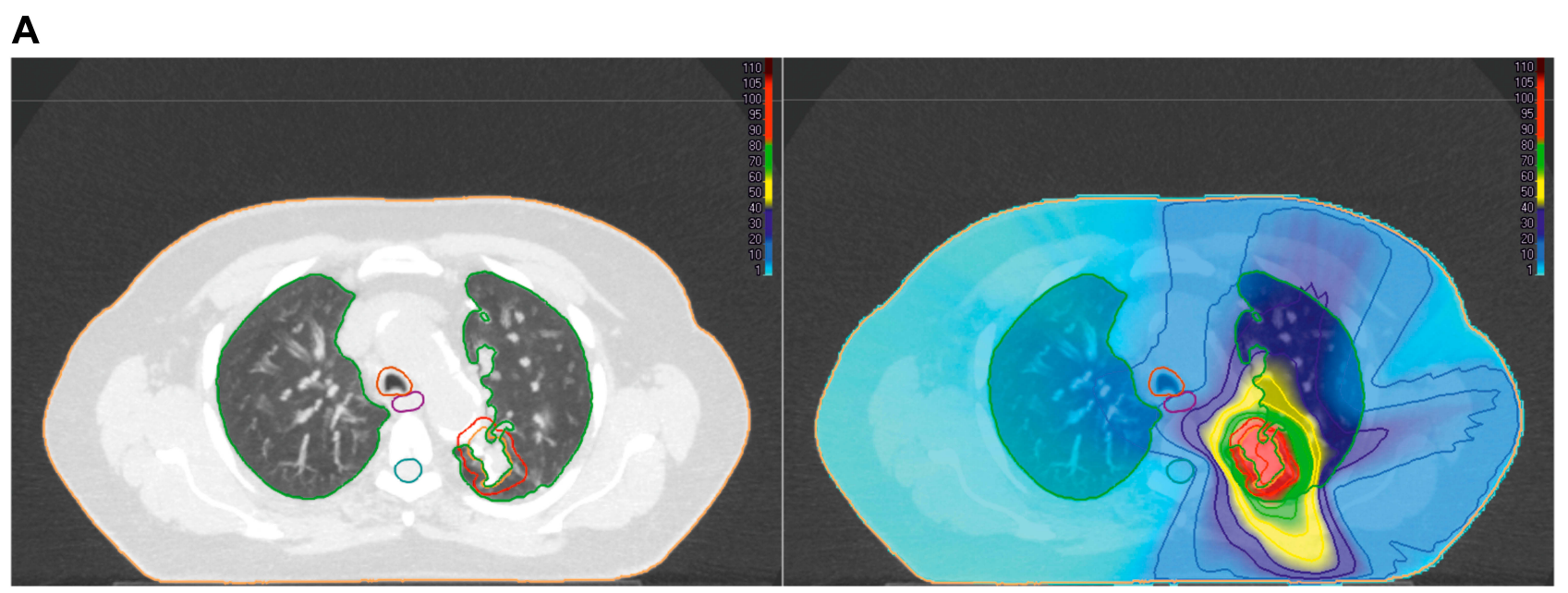

B

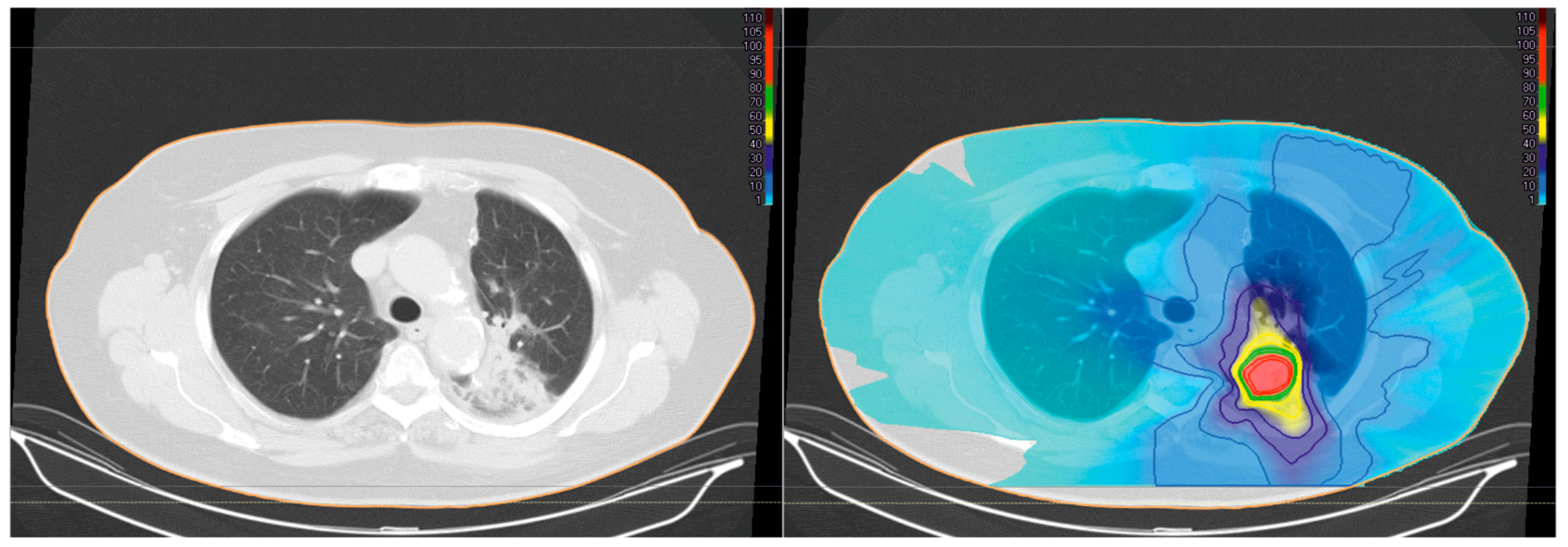

Figure 2 Radiation pneumonitis after SBRT. (A left): 78 years old female patient with histologically proven non-small cell lung carcinoma (within the red contour). Planning target volume (red contour) and organs at risk: Total lung (green), spinal cord (turquoise), oesophagus (violet), trachea (orange). (A right): Treatment plan (VMAT-technology, 5 Gy in 10 fractions, total dose $50.0 \mathrm{~Gy}$ ): Isodose lines (\% of total dose) and the dose distribution, high-dose region surrounding the tumour (red, green), step down gradient (yellow, dark blue), and a large low-dose region highlighted in blue. (B left): Consolidative changes after SBRT, suspect of tumour progression, but radiation pneumonitis was retrospectively diagnosed. (B right): A deformable image registration was used to correlate the lung changes on follow-up CT-scan with radiation dose distribution. The changes are conformal to the high-dose region.

Abbreviation: VMAT, volumetric modulated arc therapy.

Figures 4 and 5 we demonstrate local tumour control after SBRT without radiation pneumonitis resp. with discreet signs of radiation pneumonitis. Figure 6 shows a persistent tumour. The patients with radiation pneumonitis (Figures 1 and 2) are shown in Figure 7, too. We illustrate early and late radiological changes following SBRT. PET/CT findings are shown in Figures 8-10: SUVmax associated with radiation pneumonitis is shown in Figures 8 and 9, whereas in Figure 10, we demonstrate that SUVmax is associated with local recurrence.

\section{Incidences of CT Changes Following SBRT for Lung Cancer}

The CT changes following SBRT for lung cancer are classified into two stages. The early stage, which is radiation pneumonitis, occurs within 6 months after SBRT $^{15}$ with a median time of 17 weeks to the development of first CT changes. ${ }^{17}$ A classification system with five patterns of acute $\mathrm{CT}$ changes has been proposed by Linda et $\mathrm{al}^{15}$ and Kimura et al (Table 1$)^{22}$ and modified by Dahele et $\mathrm{al}^{17}$ and Palma et al (Table 2). ${ }^{21}$ In brief, the modified categories ${ }^{21}$ are diffuse consolidation (dc), patchy consolidation ( $\mathrm{pc}$ ), diffuse groundglass-opacities (dGGO), patchy ground-glass-opacities (pGGO) and no evidence of changes. Ground-glass-opacities describe an increase in pulmonary attenuation with preserved margins of vessels and airways, whereas within consolidative changes, the vessels and airways cannot be seen. ${ }^{15,21,22,29}$ The terms "diffuse" and "patchy" are defined according to size criteria ( $>5 \mathrm{~cm}$ or $<5 \mathrm{~cm}$ longest axial diameter) or to severity criteria (region contains $>50 \%$ or $<50 \%$ abnormal lung). ${ }^{21}$ 


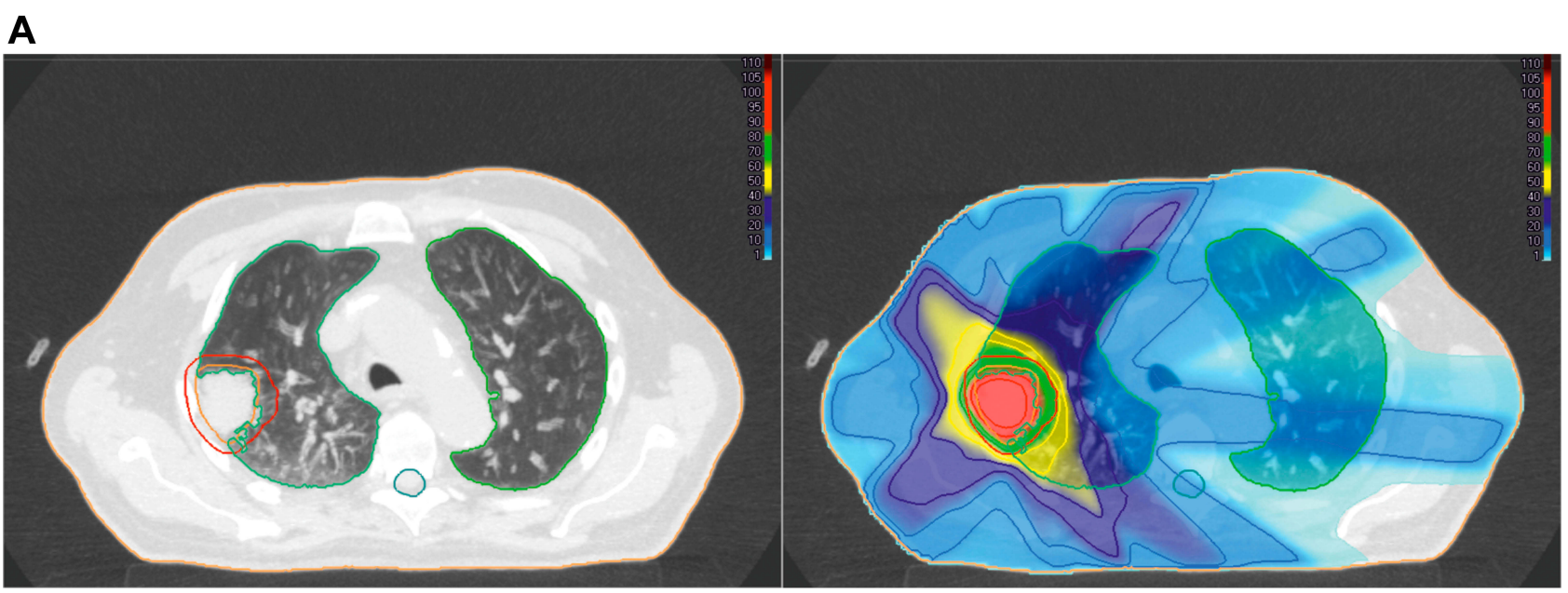

B

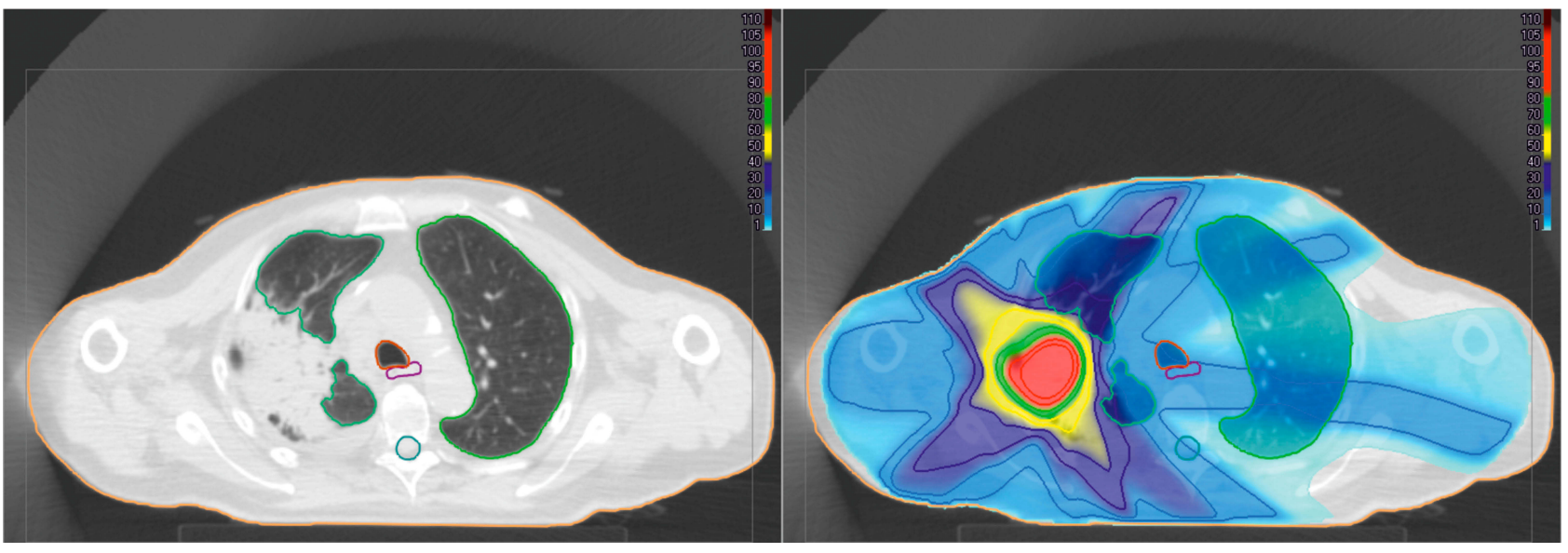

Figure 3 Radiation pneumonitis after SBRT. (A left): 80-year-old patient with histologically proven non-small cell lung carcinoma (within the red contour). Planning target volume (red contour) and organs at risk: Total lung (green), spinal cord (turquoise). (A right): Treatment plan (IMRT-technology, 9 Gy in 5 fractions, total dose 45.0 Gy): Isodose lines (\% of total dose) and the dose distribution, high-dose region surrounding the tumour (red, green), step down gradient (yellow, dark blue). The low-dose region is highlighted in blue. Using IMRT, the lung volume receiving low doses is less compared to VMAT (B left): Consolidative changes after SBRT, suspect of tumour progression, but radiation pneumonitis was retrospectively diagnosed. (B right): A deformable image registration was used to correlate the lung changes on follow-up CT-scan with radiation dose distribution. The changes are highly conformal to the high-dose region.

Abbreviations: IMRT, intensity-modulated radiotherapy; VMAT, volumetric modulated arc therapy.

Because of differences in the classification systems, a specific comparison of acute CT changes among the studies is difficult and incidences may differ: ${ }^{21}$ Kimura et $\mathrm{al}^{22}$ reported incidences of $38.5 \%$ (dc), 15.4\% (pc and GGO), 11.5\% (dGGO), $2.0 \%$ (pGGO) and $32.6 \%$ (no changes), whereas the incidences reported by Dahele et $\mathrm{al}^{17}$ were $16 \%$ (dc), 24\% (pc), $7 \%$ (dGGO), 6\% (pGGO) and 46\% (no changes). The majority of patients have consolidative patterns, GGO is less common and the overall incidence of acute changes is approximately $60 \% .{ }^{20}$ Due to the dose distribution, these changes correspond to the shape of the tumour and it could be difficult to distinguish those benign findings (Figures 1B, 2B, and 3B) from early local recurrence, especially in cases of diffuse or patchy consolidation. ${ }^{15}$ Six months after SBRT, the late stage begins, and CT changes appear as radiation fibrosis. ${ }^{15}$ The morphology may change over the years. ${ }^{17}$

Acute RP is shown in Figures $1 \mathrm{~B}, 2 \mathrm{~B}$, and $3 \mathrm{~B}$. We used a deformable image registration (Figure $1 \mathrm{C}$, right) to correlate the lung changes with the radiation dose distribution. The changes are conformal to the high- and mid-dose region. A rigid registration cannot account for lung volume and tumour position changes on follow-up CT-scans (Figure $1 \mathrm{C}$, left). ${ }^{23}$ The deformable image registration is more accurate than the rigid registration and the images correlate well with each other.

\section{Impact of Irradiation Technology}

The technical-physical progress of radiation oncology led to distinct changes of dose distribution in patients. 
A

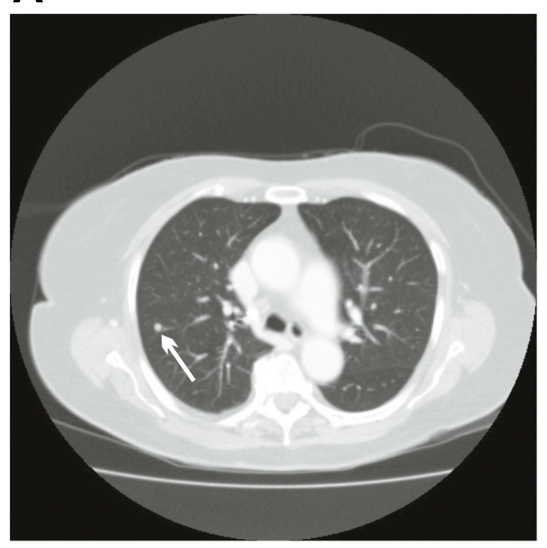

B

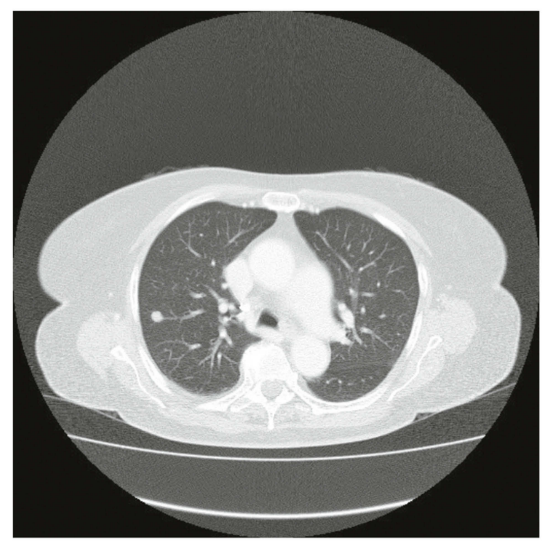

C

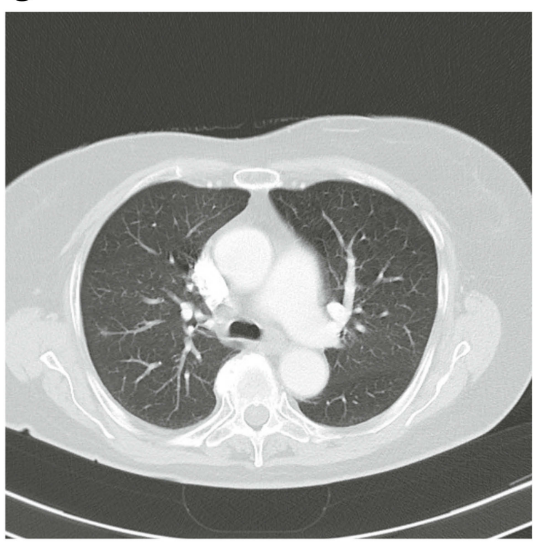

D

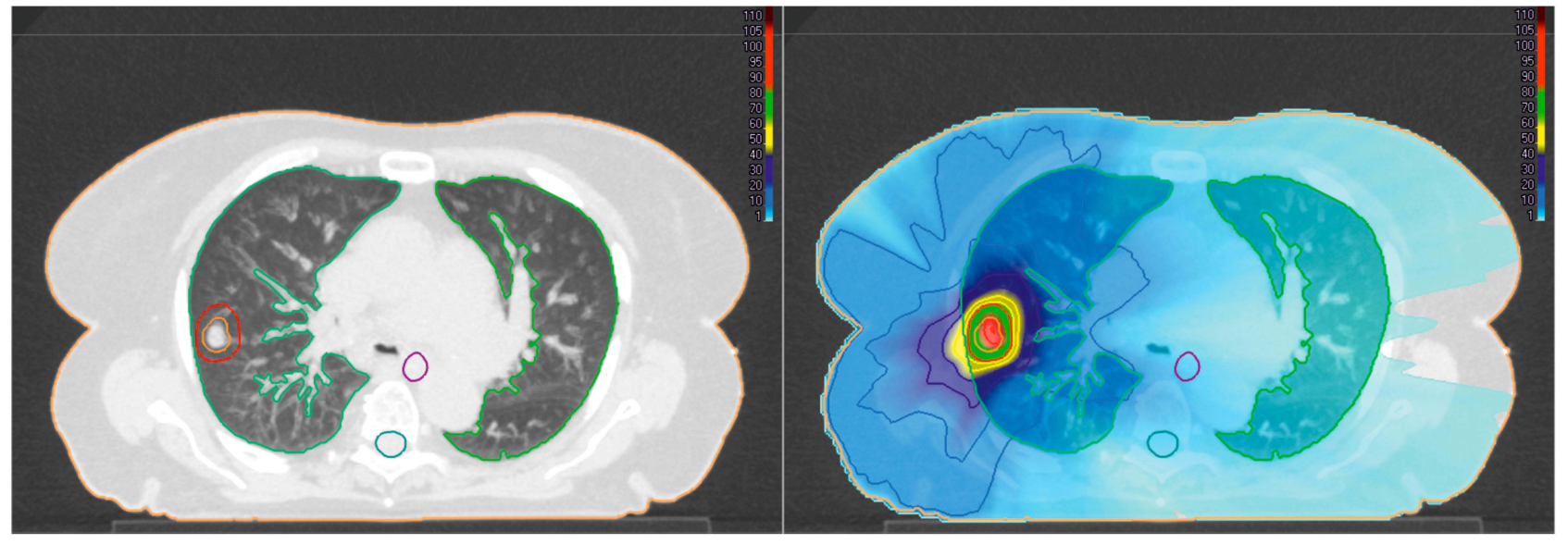

E

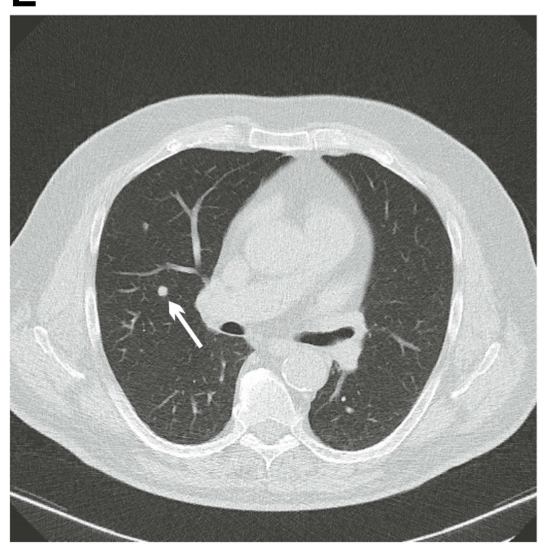

F

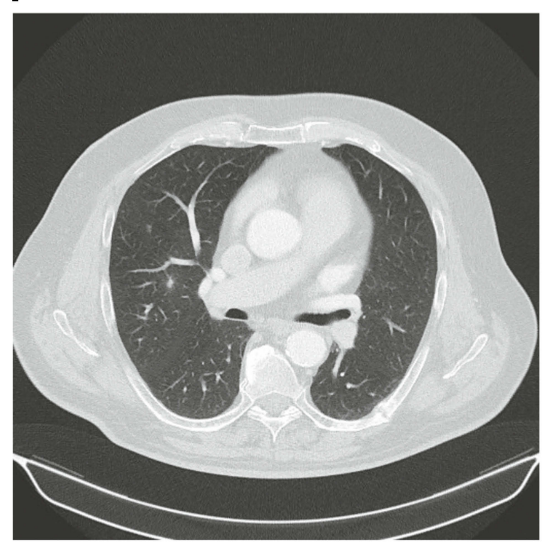

Figure 4 Local control after SBRT. (A-D): (A): 86-year-old woman with a metachronous $(5 \mathrm{~mm})$ lung metastasis of colon carcinoma (white arrow). Due to the age, no histological verification was done. (B): Follow-up after 3 months. Increase in size to $8 \mathrm{~mm}$, decision for SBRT. (C): Tumour response 3 months after SBRT, size decrease by $2 \mathrm{~mm}$, no evidence of radiation pneumonitis. (D left): Tumour within the planning target volume (red contour) and organs at risk: Total lung (green), spinal cord (turquoise) and oesophagus (violet).(D right): Treament plan: High-dose region surrounding the tumour (red, green), step down gradient (yellow, dark blue), and a large low-dose region highlighted in blue. The patient was treated with a dose of $15 \mathrm{~Gy}$ in 3 fractions (total dose $45.0 \mathrm{~Gy}$ ). (E and F): Another patient treated with SBRT (7.5 Gy in 8 fractions, total dose $60.0 \mathrm{~Gy}$ ) for lung metastasis of colon carcinoma (white arrow) had tumour response on follow-up at 3 months after SBRT. No radiation pneumonitis.

Volumetric modulated arc therapy (VMAT, Figures 1A tissue receiving low doses compared to other and 2A) improves treatment time by quick dose applicatechniques. ${ }^{24}$ Besides VMAT, older techniques such as tion, but it tends to increase the volume of normal lung three-dimensional conformal radiotherapy (3DC-RT) and 
A

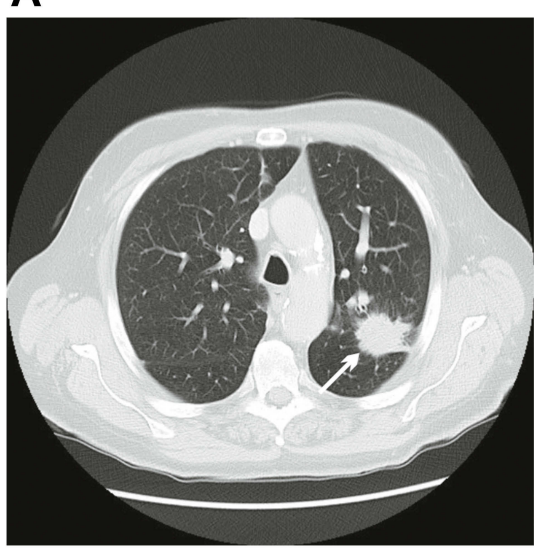

B

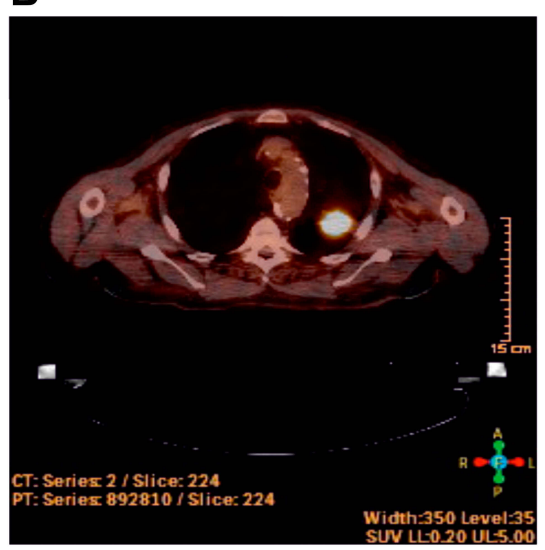

C

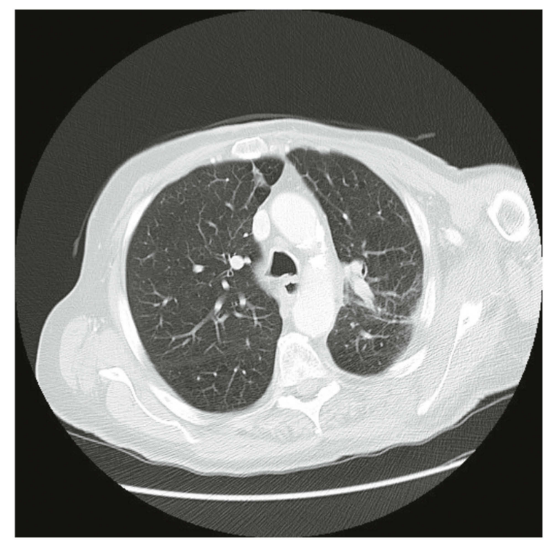

D

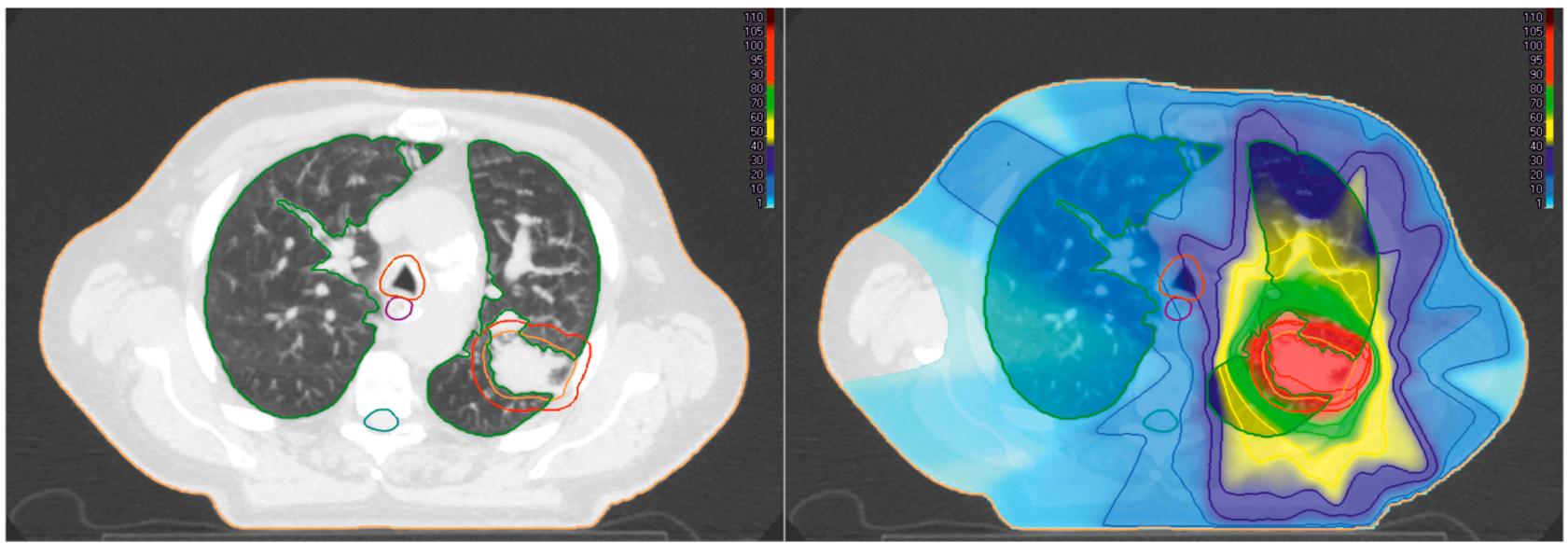

Figure 5 Local control with discreet radiation pneumonitis. (A): 78-year-old patient with histologically confirmed non-small cell lung carcinoma (white arrow). Size about 30 mm. (B): PET/ CT for treatment planning. SUVmax = 14.94. (C): Tumour response 3 months after SBRT. Discreet radiation pneumonitis. The patient was asymptomatic. (D left): Tumour within the planning target volume (red contour) and organs at risk: Total lung (green), spinal cord (turquoise), oesophagus (violet) and trachea (orange). (D right): Treatment plan (IMRT-technology, I2 Gy in 5 fractions, total dose $60.0 \mathrm{~Gy}$ ): Isodose lines (\% of total dose) and the dose distribution, high-dose region surrounding the tumour (red, green), step down gradient (yellow, dark blue), and a large low-dose region highlighted in blue.

Abbreviation: IMRT, intensity-modulated radiotherapy.

"step-and-shot" intensity-modulated radiation therapy (IMRT, Figure 3A) are in use. $^{21} \mathrm{~A}$ dose distribution highly conformal to the tumour can be achieved (Figure 4D), but because of the differences in dose distribution, different patterns of radiological changes might result. $^{14}$ To investigate this assumption, Palma et $\mathrm{al}^{21}$ compared patterns of acute RP after SBRT with VMAT and 3DC-RT, and they evaluated the severity of clinical RP according to CTCAE v3. The authors reported acute CT changes in 43 of 75 patients $(57.3 \%)$ which were mainly consolidative, but no significant difference in the pattern of CT changes between VMAT and 3DC-RT was found $(\mathrm{p}=0.47)$. Symptomatic pneumonitis was uncommon, only 4 patients $(5.3 \%)$ had grade 2 or 3 pneumonitis, and again no significant differences were found between them $(\mathrm{p}=0.99)$. Similarly, Senthi et $\mathrm{al}^{25}$ and Badellino et $\mathrm{al}^{14}$ reported no differences of acute CT changes between VMAT and 3DC-RT $\left(\mathrm{p}=0.23^{25}\right.$ respectively $\mathrm{p}=0.55^{14}$ ) with low rates of severe clinical RP. In conclusion, the techniques are superimposable with low rates of severe clinical pneumonitis.

\section{High-Risk CT Features for Detection of Local Recurrence}

CT scans after SBRT are recommended for evaluating tumour response (Figures 4A-C, E, F, 5A, C, 8C, D, and 10D, F), excluding tumour progression (Figures 6A,C and 7A, B) or detecting tumour progression (Figure 10A, C, F, and G), and for detecting benign early (Figure $7 \mathrm{C}$ and $\mathrm{H}$ ) and late radiological changes (Figure 7D-F). Albeit such benign changes 
A

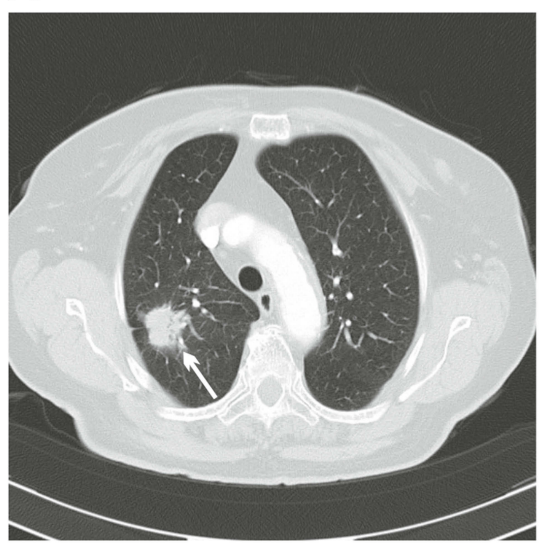

B

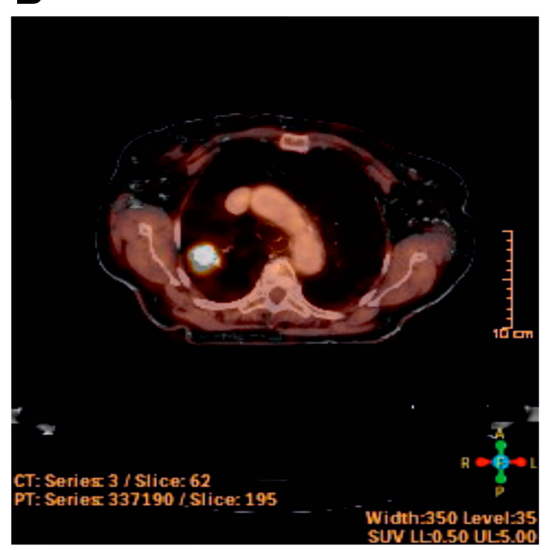

C

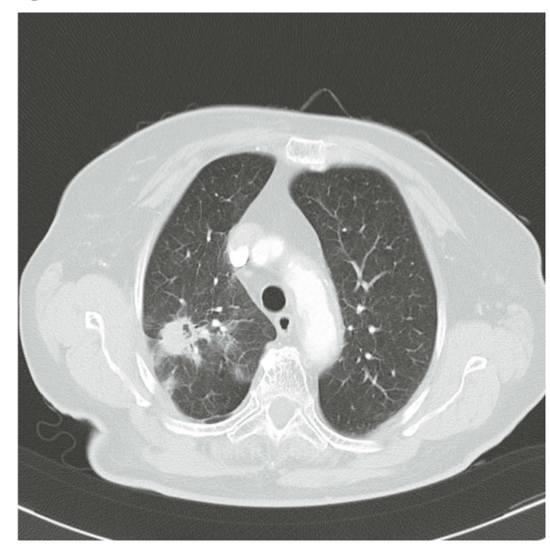

D

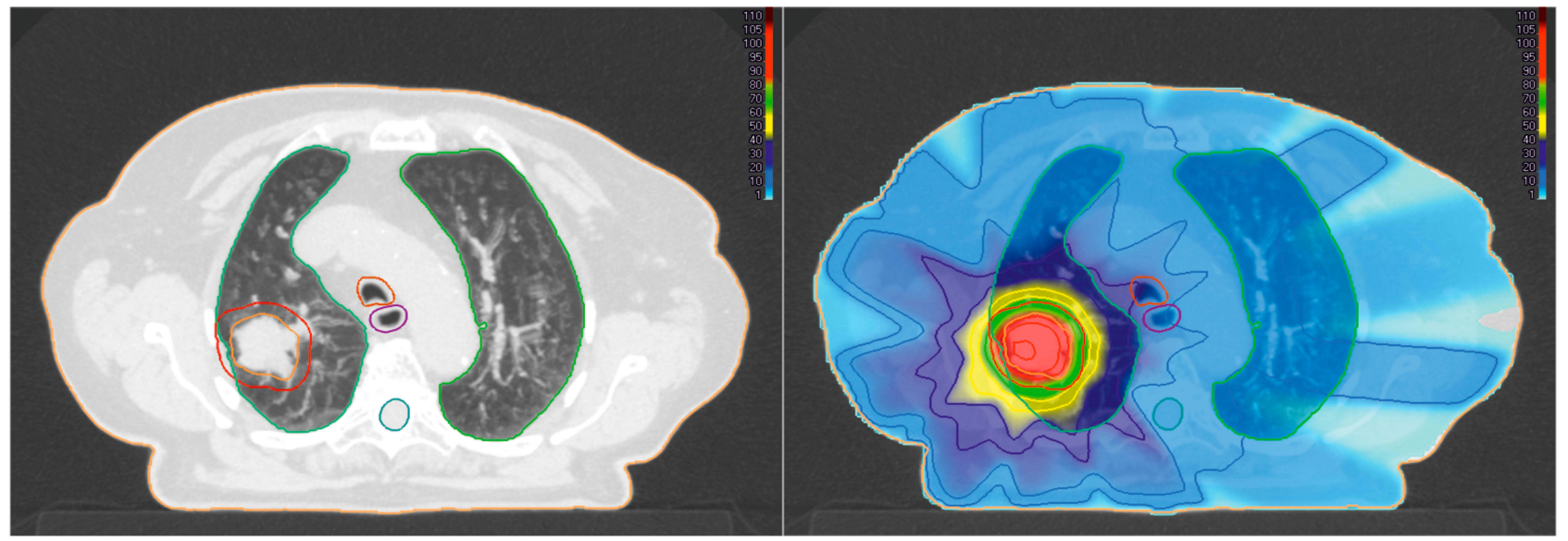

Figure 6 PET for tumour detection. (A): 89-year-old female patient with a tumour-related finding on a CT-scan (size 23 mm, white arrow), no histological examination was performed due to poor constitution. (B): PET/CT for treatment planning with a SUVmax = I7.I, suspicious of a tumour. SBRT was done. (C): Stable disease at 3 months with radiological radiation pneumonitis. On follow-up (at 12 months), the tumour failed to decline (data not shown). (D left): Tumour within the planning target volume (red contour) and organs at risk: Total lung (green), spinal cord (turquoise), oesophagus (violet) and trachea (orange). (D right): Treatment plan (IMRT-technology, 7 Gy in 5 fractions, total dose 35.0 Gy): Isodose lines (\% of total dose) and the dose distribution, high-dose region surrounding the tumour (red, green), step down gradient (yellow, dark blue), and a large low-dose region highlighted in blue.

Abbreviation: IMRT, intensity-modulated radiotherapy.

after SBRT for lung cancer are common, local recurrence is rare. $^{26}$ With a median time of 14.9 months, only $4.9 \%$ of patients experienced local failure within 2 years. ${ }^{27}$ In clinical practice, RECIST criteria $1.1^{28}$ are used for response assessment, but RECIST is not reliable until 15 months postSBRT. $^{29}$ Huang et $\mathrm{al}^{20,30}$ reported CT findings after SBRT suggestive of recurrence and later defined as high-risk CT features (HRF), including a bulging margin, enlargement after 12 months, loss of air bronchogram, appearance of pleural effusion, linear margin disappearance, enlarging opacity, lymph node enlargement and cranio-caudal growth. The study group ${ }^{30}$ matched 12 patients (with pathology proven local recurrence) to 24 patients with benign changes. All these factors were significantly associated with local recurrence $(\mathrm{p}<0.01)$. The best indicators were an enlarging opacity after 12 months (sensitivity 100\%, specificity 83\%) and cranio-caudal growth (sensitivity 92\%, specificity 83\%). With an increasing number of HRFs, specificity increases and sensitivity decreases. Nevertheless, early detection is disputable. Although some of the HRFs appear 6 months after SBRT, the median time was 22 months for "enlargement after 12 months", respectively, 13 months for "cranio-caudal growth". ${ }^{30}$ These results were validated by Peulen et $\mathrm{al}^{31}$ and Frakulli et al. ${ }^{19}$ Huang et $\mathrm{al}^{20,30}$ also investigated the value of metabolic findings. A normal response is characterised by a stable SUV or a decline to background SUV after SBRT, but a transient increase of SUVmax within 6 months postSBRT due to acute inflammation of lung tissue is also possible. Especially within the first 6 months after SBRT, recurrence should be considered not until SUVmax is greater than $5 .^{20}$ Based on these results, an imaging follow-up algorithm was proposed including the number of HRFs and a SUVmax 
Table I Early Radiological Changes According to Radiation Pneumonitis After SBRT

\begin{tabular}{|l|l|}
\hline Name & Description \\
\hline Diffuse consolidation & $\begin{array}{l}\text { Diffuse, homogeneous increase in } \\
\text { pulmonary parenchymal attenuation that } \\
\text { obscures the margins of vessels and } \\
\text { airway walls and completely fills the } \\
\text { high-dose region. Frequently, air } \\
\text { bronchogram can be detected within } \\
\text { the area of consolidation, a sign that } \\
\text { suggests that the air within affected } \\
\text { alveoli has been replaced by exudates } \\
\text { and cells. }\end{array}$ \\
\hline $\begin{array}{l}\text { Diffuse ground-glass } \\
\text { opacity }\end{array}$ & $\begin{array}{l}\text { Hazy increased attenuation of lung, with } \\
\text { preservation of bronchial and vascular } \\
\text { margins, that completely fills the high- } \\
\text { dose region. }\end{array}$ \\
\hline Patchy consolidation and \\
ground-glass opacity & $\begin{array}{l}\text { Patchy areas of hazy and dense } \\
\text { increased attenuation of lung, not } \\
\text { completely filling the high-dose region. }\end{array}$ \\
\hline Patchy ground-glass & $\begin{array}{l}\text { Patchy areas of hazy increased } \\
\text { attenuation interspersed in normal } \\
\text { parenchyma, not completely filling the } \\
\text { high-dose region. }\end{array}$ \\
\hline No changes & $\begin{array}{l}\text { No evidence of increased density within } \\
\text { the high-dose region. }\end{array}$ \\
\hline
\end{tabular}

Notes: Data from Linda et al ${ }^{15}$ and Kimura et al. ${ }^{22}$

threshold of $5 .^{30}$ This algorithm might help to detect early recurrences within 6 months, but this is ambiguous regarding the median time of appearance of the benign CT changes.

\section{CT Texture Analysis for Distinguishing Local Recurrence from Radiation Pneumonitis CT Density Measurements Correlate with CT Changes After SBRT}

Palma et $\mathrm{al}^{32}$ used a deformable registration algorithm for measuring early $\mathrm{CT}$ density changes between planning CT and diagnostic follow-up CT 3 months after SBRT for the lung (Figure 1C, right). They found a strong correlation between increased lung density changes in the peritumoral region and the severity of radiological pneumonitis $(\mathrm{p}<0.001)$. By contrast, no correlation was found between severity of radiological pneumonitis and the whole ipsilateral lung $(\mathrm{p}=0.22)$. In conclusion, the peritumoral region seems to be appropriate for ongoing investigation.

\section{Appearance Measurements Is Superior to} Size Measurements

As previously reported, distinguishing local recurrence from benign $\mathrm{CT}$ changes is feasible by identification of HRFs on post-SBRT CT, but early detection of local recurrence remains difficult. Delayed detection of local recurrence impairs the opportunities for salvage treatment options considerably. Mattonen et $\mathrm{al}^{29}$ investigated measures of sizes (mean 3D volume and mean RECIST) and appearance measurements (mean CT density and mean standard deviation of CT density) on the CT for treatment planning and on followup CT. Patients were considered to have a recurrent tumour $(n=11$, pathology proven in $n=8)$ or benign $C T$ changes $\left(n=13\right.$, non-recurrent, $\left.\operatorname{see}^{17}\right)$. Based on the results of Palma et al, ${ }^{32}$ two regions of interest were manually contoured: the consolidative region (increased density without visibility of vessels, Figure 7C) and the ground glass opacities (increased density with visibility of vessels, Figure $7 \mathrm{H}$ ). Before SBRT, no significant differences were found. Nine months after SBRT, patients with recurrence had significantly denser mean density changes in consolidative region than the non-recurrence patients $(-96.4 \pm 32.7 \mathrm{HU}$ vs $-143.2 \pm 28.4 \mathrm{HU}, \mathrm{p}=0.046)$. Additional, in the GGO at that point of time, the recurrence group had a higher standard deviation of CT density $(210.6 \pm 14.5 \mathrm{HU}$ vs $175.1 \pm 18.7 \mathrm{HU}$, $\mathrm{p}=0.0078)$. Significant differences in RECIST $(\mathrm{p}=0.028)$ and $3 \mathrm{D}$ volume $(\mathrm{p}=0.03)$ were found 15 months after SBRT. In conclusion, size and appearance measurement may distinguish benign CT changes from recurrence after 9 months, compared to RECIST after 15 months.

\section{Appearance Measurements Can Predict Recurrence Within 5 Months}

To validate these findings, Mattonen et al conducted an ongoing study. ${ }^{13}$ Using the same patients again, ${ }^{29}$ the objective of this study was to analyse the accuracy of size and appearance measurements for distinguishing local recurrence from benign CT changes. Once more, the two regions of interest were manually segmented. In the consolidative region, two measures of size (longest axial diameter/RECIST and 3D volume) were taken. A total of nine appearance features were calculated in the GGO: Two first-order texture features (FOF, mean $\mathrm{CT}$ density and standard deviation of CT density), and seven second-order texture features (SOF). FOFs are histogram-based features which describe the distribution of values of individual voxels without concern for relationship, ${ }^{33,34}$ 
A

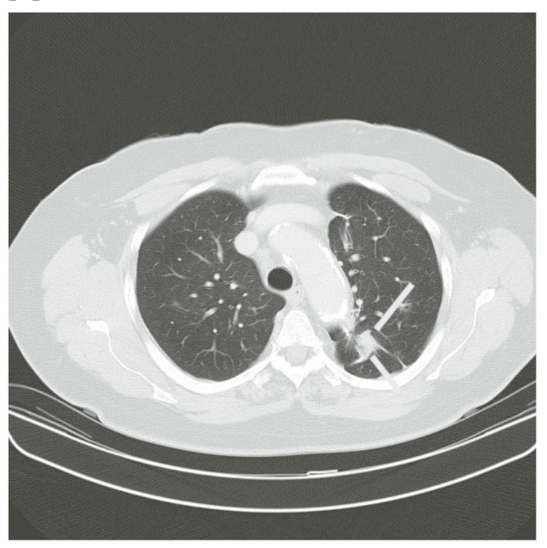

D

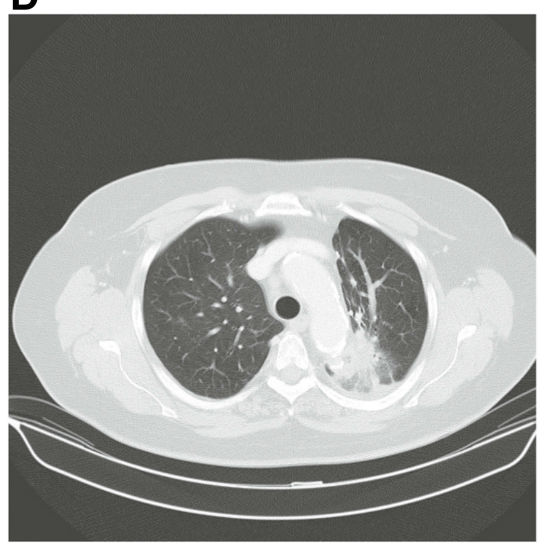

G

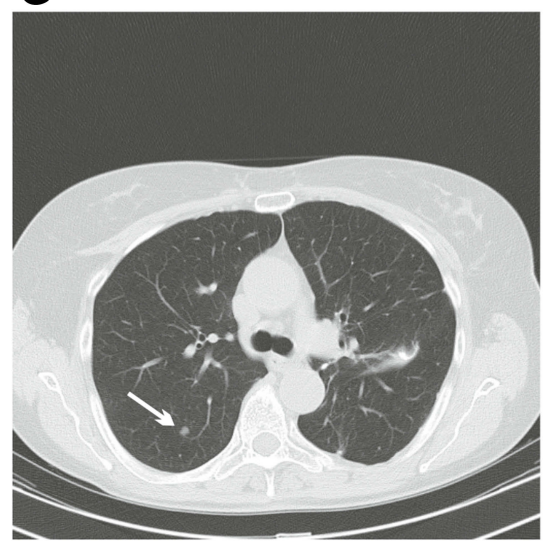

B

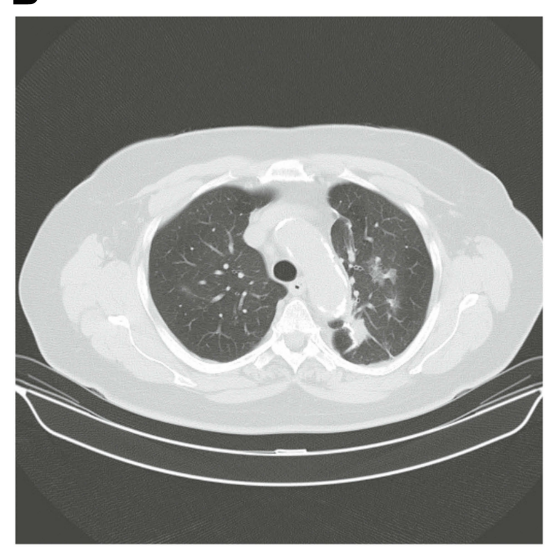

E

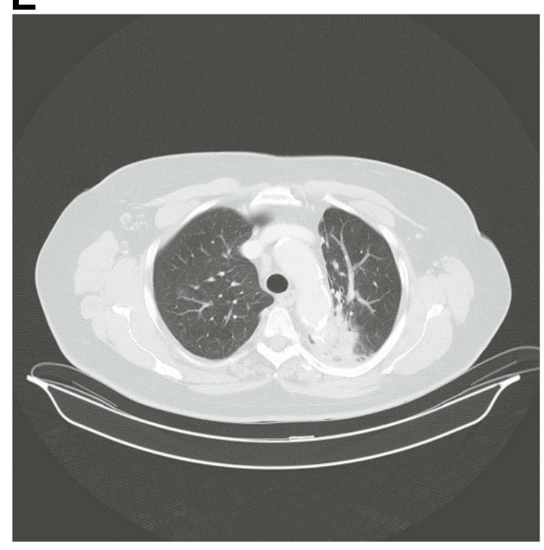

C

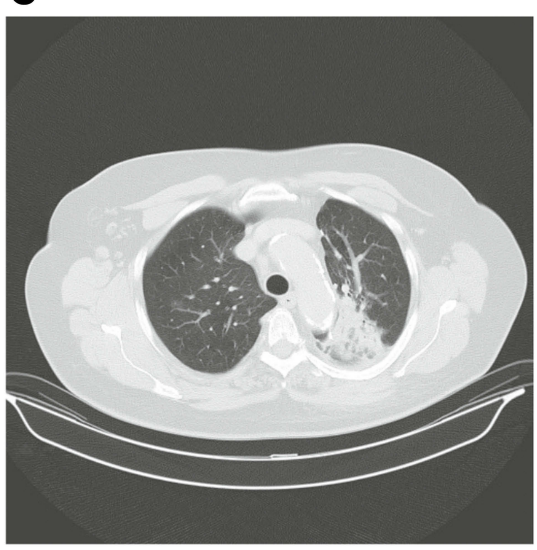

$\mathbf{F}$

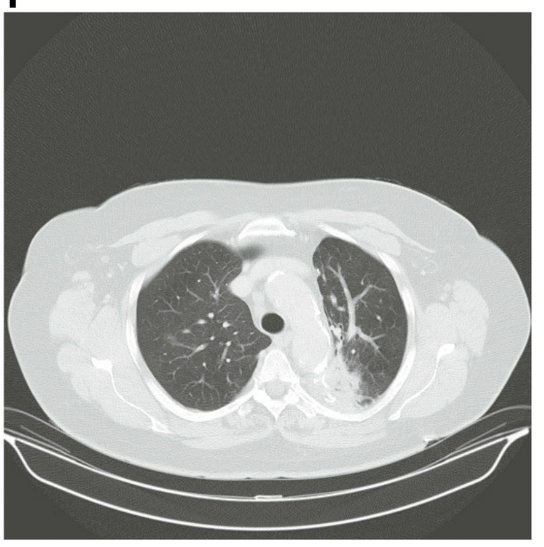

H

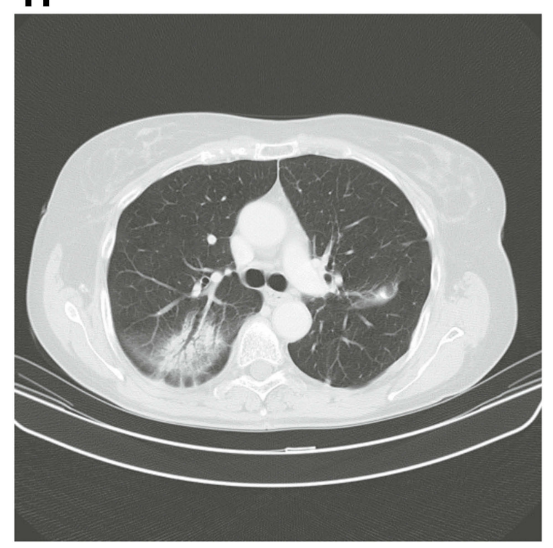

Figure 7 Radiation pneumonitis after SBRT. (A-F, see Figure 2): Consolidative changes. (A): A 78 years old female patient with histologically proven non-small cell lung carcinoma (white lines) was treated with SBRT, 5 Gy in 10 fractions, total dose 50.0 Gy. (B): Stable disease I month after SBRT. (C): Enlarging consolidative changes 5 months after SBRT, suspected tumour progression. Decision to wait. (D-F): The CT-changes did not change of time (D: 9 months after SBRT, (E) 12 months, (F) I8 months). Thus, radiation pneumonitis resp. radiation fibrosis was more likely than a recurrent tumour. ( $\mathbf{G}$ and $\mathbf{H}$, see Figure I): Ground-glass opacities. (G): A 74-year-old female patient had a parathyroid carcinoma with a lung metastasis (white arrow). SBRT was performed. (H): A CT-scan 3 months after SBRT revealed radiographic radiation pneumonitis since ground-glass opacities were seen. No tumour detection at follow-up (images not shown). Thus, radiation pneumonitis was more likely than recurrence of a tumour.

whereas SOFs describe relationships between voxels including a grey-level co-occurrence matrix (GLCM). ${ }^{33,34}$ To summarize within 5 months after SBRT, the FOF mean density $(p=0.035)$ and the best performing SOFs energy $(\mathrm{p}=0.036)$, entropy $(\mathrm{p}=0.034)$ and inertia $(\mathrm{p}=0.036)$ were significantly different between the groups. The accuracy of SOF, FOF, 3D volume and RECIST was $77 \%, 73 \%, 60 \%$ and $57 \%$ (two-fold crossvalidation). Similar findings resulted within the 5-8 months 
A

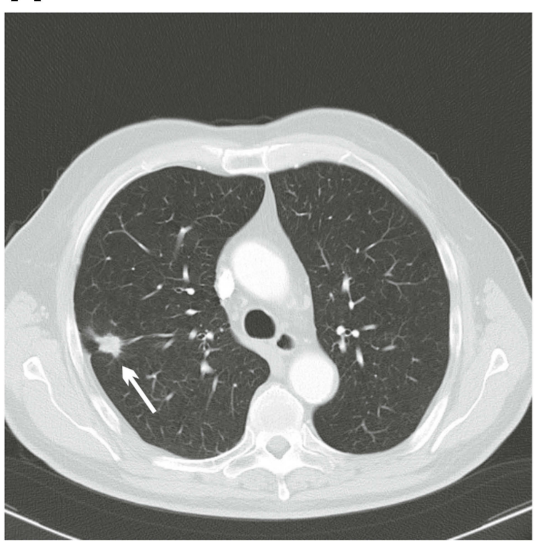

D

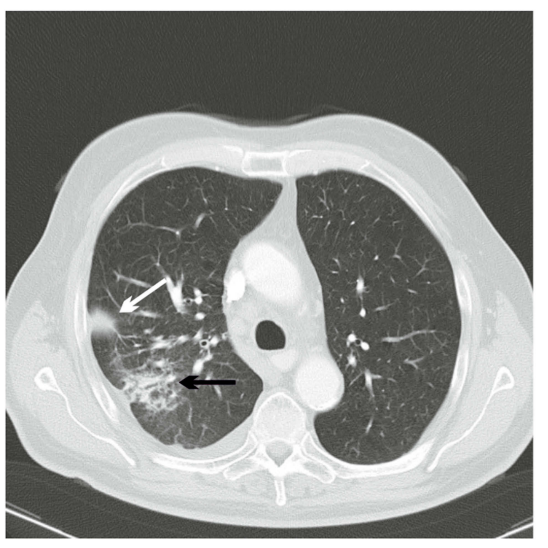

B

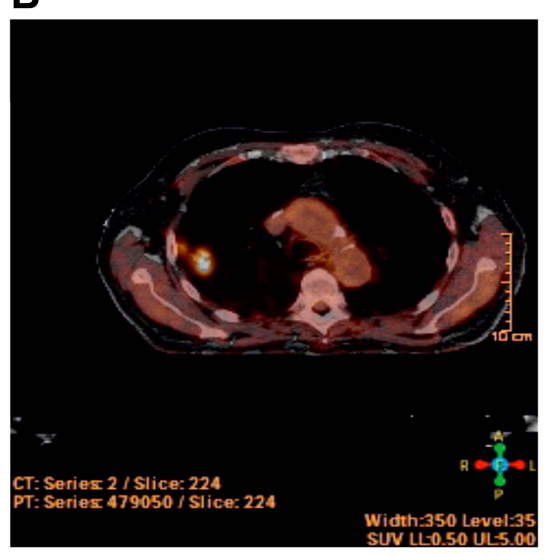

E

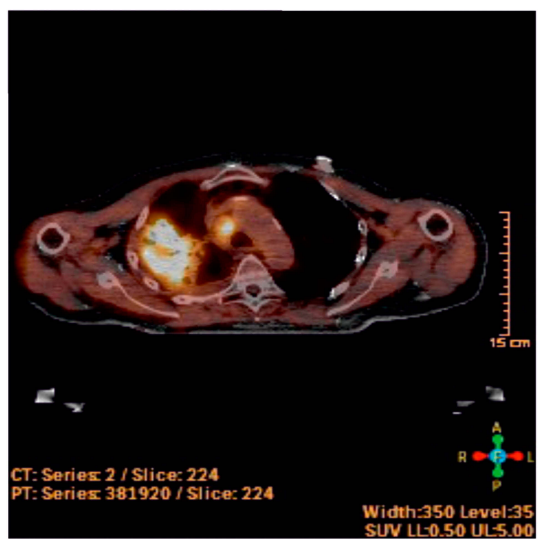

C

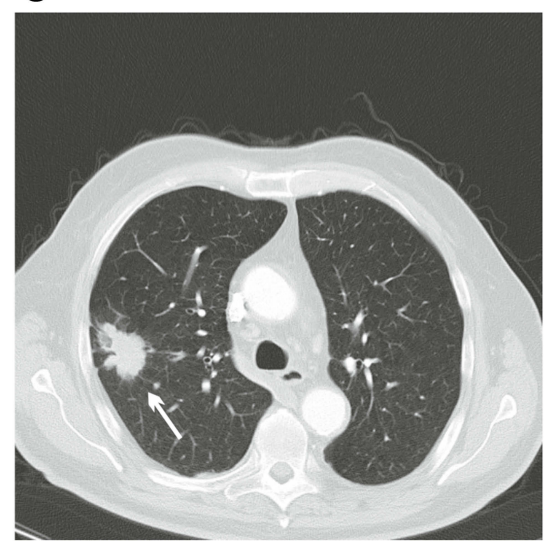

Figure 8 SUVmax persistence associated with radiation pneumonitis (see Figure 3). (A and B): 80-year-old patient with histologically confirmed non-small cell lung carcinoma (white arrow). CT (size $14 \mathrm{~mm}$ ) and PET/CT (SUVmax = 7.56) at the time of diagnosis. Therapy was rejected. (C): Follow-up I year later, enlarging tumour mass (increase in size to $39 \mathrm{~mm}$, white arrow). SBRT was performed ( $9 \mathrm{~Gy}$ in 5 fractions, total dose $45.0 \mathrm{~Gy}$ ). (D): Follow-up I month later with radiological radiation pneumonitis (black arrow) and tumour response (white arrow, size $6 \mathrm{~mm}$ ). (E): Increasing consolidation on CT at 3 months, suspect of relapse. PET/CT was performed $(\mathrm{SUVmax}=8.27$ ) and a biopsy was taken, but the histology was negative (no malignity). SUVmax persisted without evidence of a recurrent tumour. Radiation pneumonitis was diagnosed. (paratracheal increased metabolic activity with histologically confirmed lymph node metastasis, once again radiotherapy was performed).

interval demonstrating robustness and repeatability. In conclusion, appearance measurements can distinguish local recurrence from benign CT changes within 5 months after SBRT, and this is more accurate than size measurements.

\section{Radiomics-Based Assessment Using a Semiautomatic Segmentation Algorithm for Distinguishing Local Recurrence from Radiation Pneumonitis}

\section{Semiautomatic Segmentation Algorithm Is Time Sparing}

Radiomics describes the extraction of large amounts of image features from radiographic images and the analysis of these data for decision support. ${ }^{33,35}$ The extracted features are calculated within a region of interest, ${ }^{34}$ for example, the consolidative region or the GGO. In clinical practice, delineation of the consolidative regions tends to be simple, but contouring of the GGO is time-consuming and more difficult. Even though robustness to the variability of manually GGO delineation was reported, ${ }^{13}$ delineation takes time and an interoperator variability is expected due to barely recognizable boundaries of GGO. ${ }^{36}$ Using a semiautomatic segmented periconsolidative region, which is an expansion of the consolidative region, time can be saved. As this region intends to retrieve GGO tissue, results comparable to manually contoured GGO are achieved. ${ }^{37,38}$

\section{Semiautomatic Segmentation Algorithm Allows Distinguishing Within 6 Months}

Mattonen et al established a semiautomatic segmentation algorithm for early prediction of lung cancer recurrence after SBRT using second-order features. ${ }^{37}$ First, accuracy of recurrence 
A

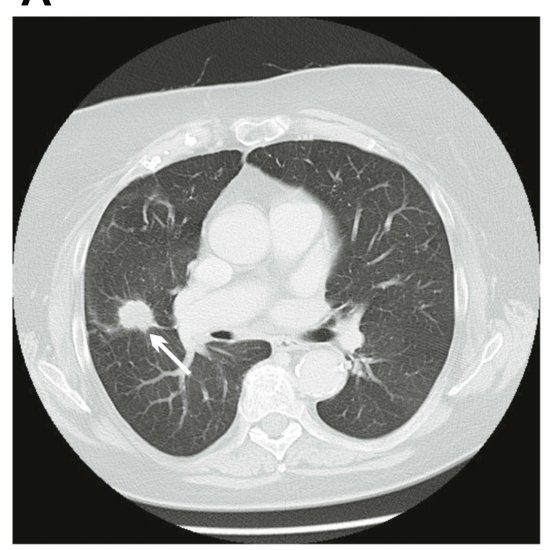

D

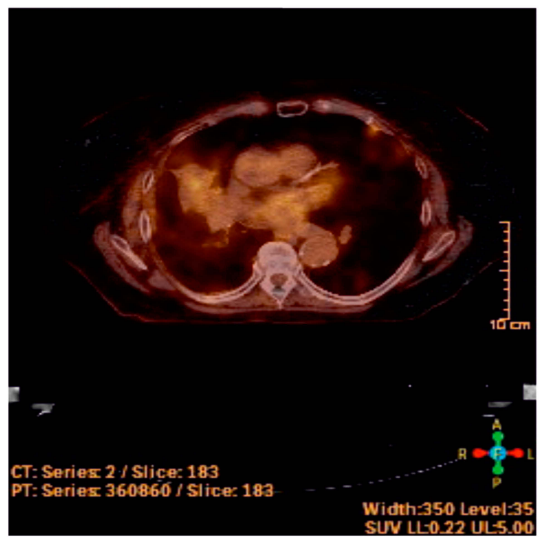

G

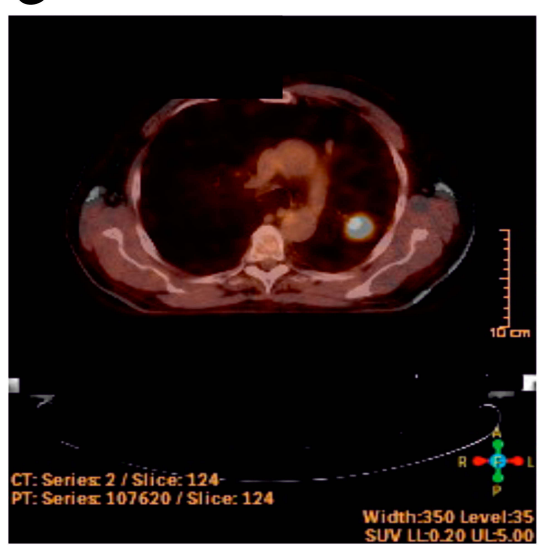

B

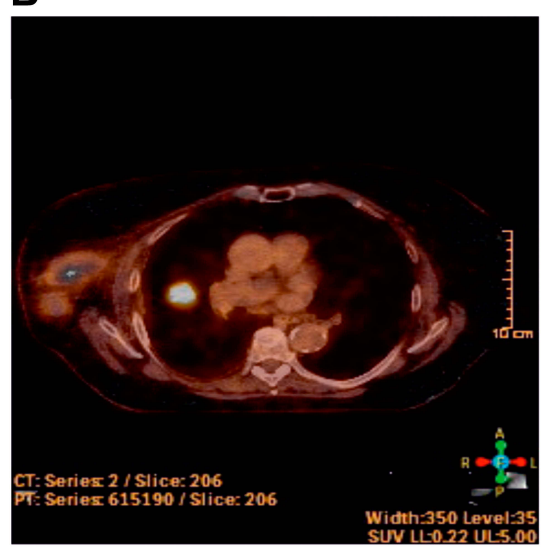

E

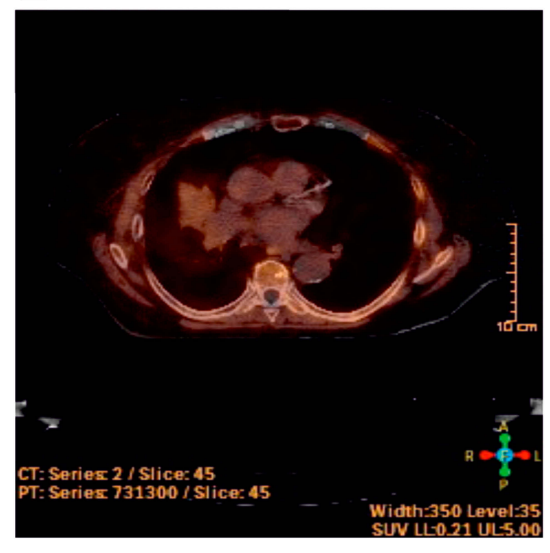

H

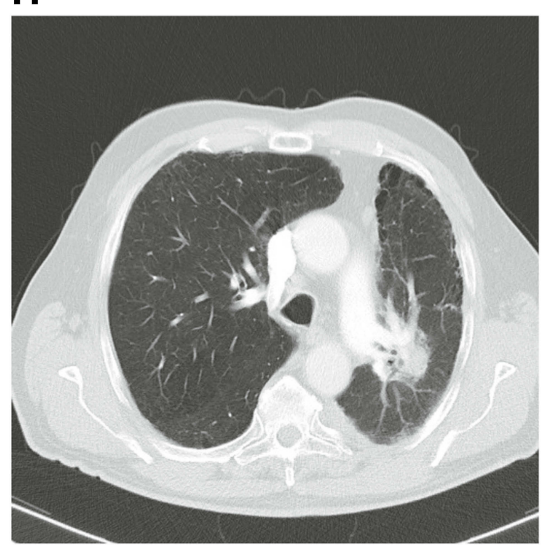

C

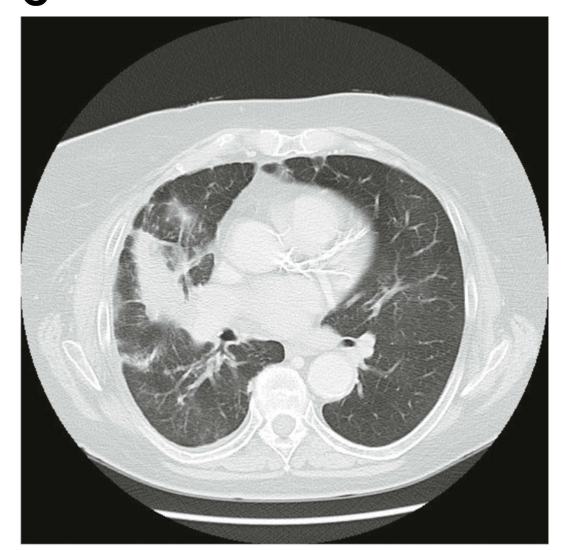

F

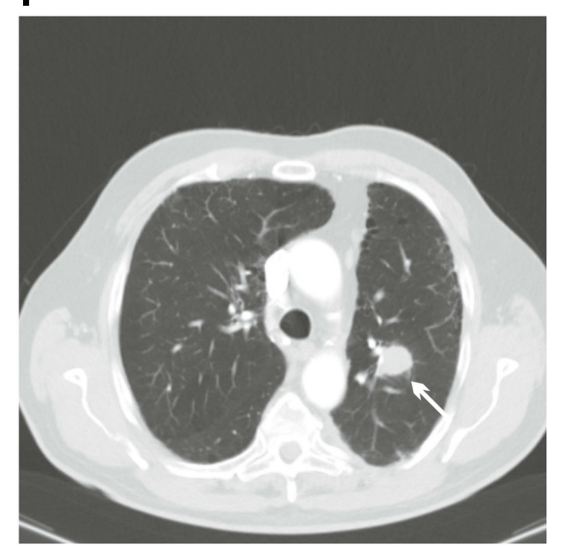

I

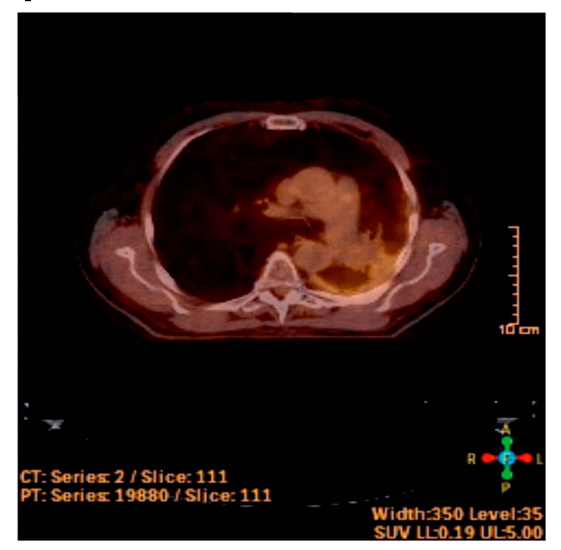

Figure 9 PET/CT for distinguishing radiation pneumonitis from local recurrence. (A-E): (A and B): 82-year-old female patient with histologically confirmed non-small cell lung cancer. CT (size $17 \mathrm{~mm}$, white arrow) and PET/CT (SUVmax = 12.74) at the time of diagnosis. SBRT was done with a dose of $7.5 \mathrm{~Gy}$ in 8 fractions (total dose $60.0 \mathrm{~Gy}$ ). (C): On follow-up 3 months after SBRT, a CT-scan was suspect of tumour progression (consolidative region, size $39 \mathrm{~mm}$ ). (D): A PET/CT at this time point was done, SUVmax was 5.25 . A biopsy was taken, but it was negative. A follow-up PET was recommended. (E): At 6 months after SBRT, SUVmax $(=2.25)$ declined. Thus, elevated SUVmax was recognized and radiation pneumonitis was retrospectively diagnosed. (F-I): (F and $\mathbf{G}$ ): 80-year-old patient treated with SBRT. Lesion size was $22 \mathrm{~mm}$ (white arrow) and the SUVmax was I6.38. The dose was $7.5 \mathrm{~Gy}$ in 7 fractions (total dose $52.5 \mathrm{~Gy}$ ). (H): A CT 3 months after SBRT was suspect of tumour progression and a PET was recommended. (I): SUVmax was $3.5 \mathrm{I}$ at 6 months after SBRT. A recurrent tumour resp. tumour progression was unlikely and radiation pneumonitis was diagnosed. On follow-up, the CT changes did not change (data not shown). 
A

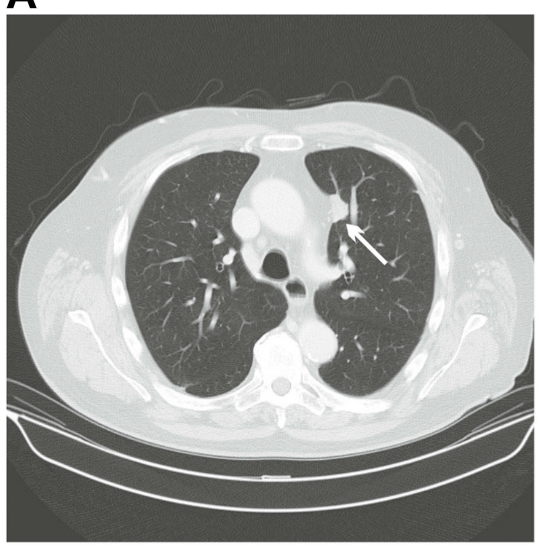

D

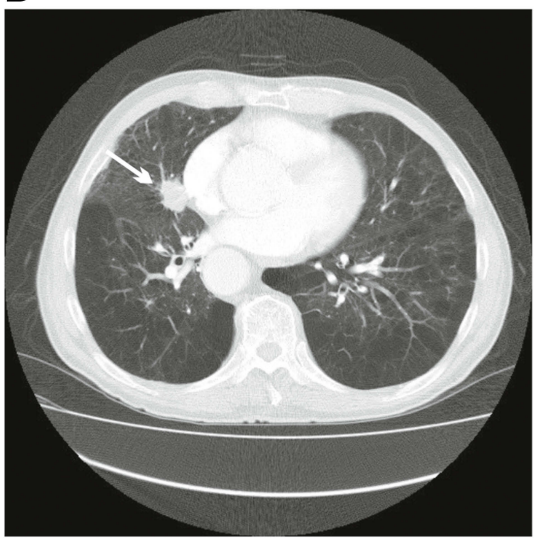

G

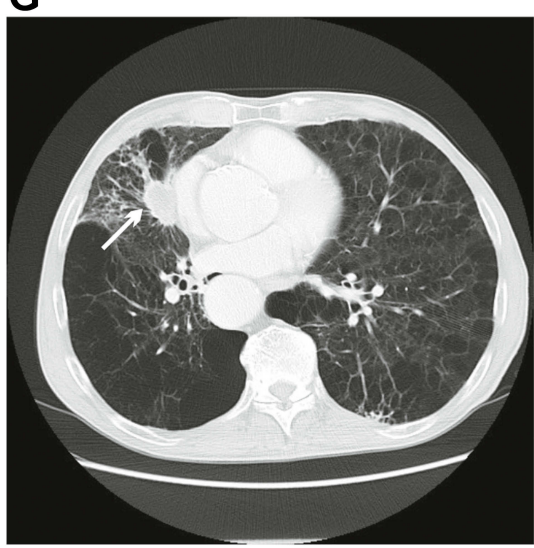

B

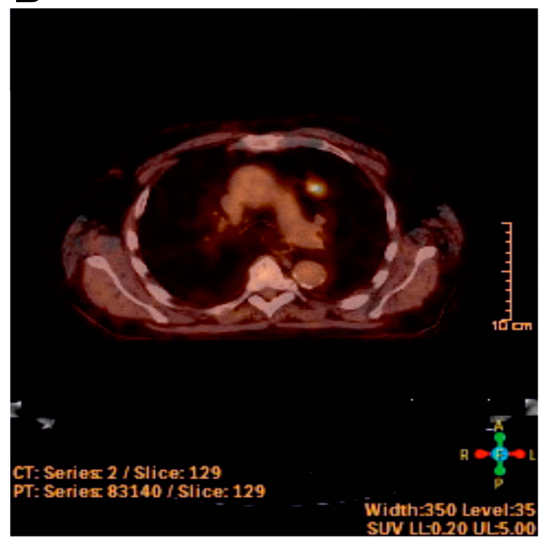

E

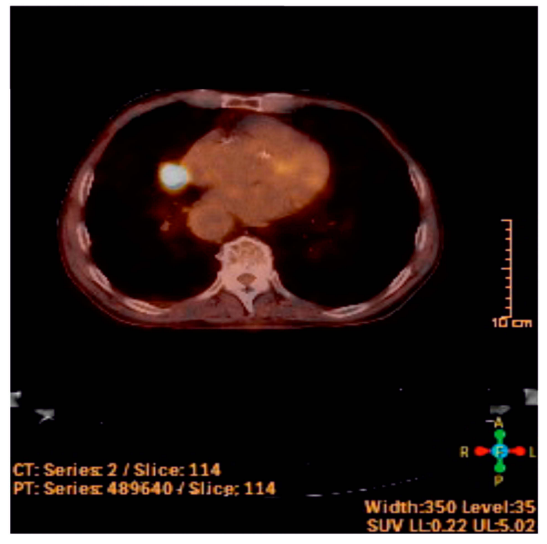

H

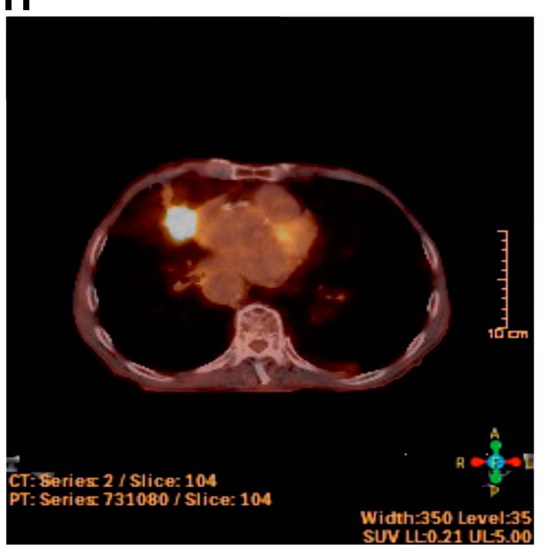

C

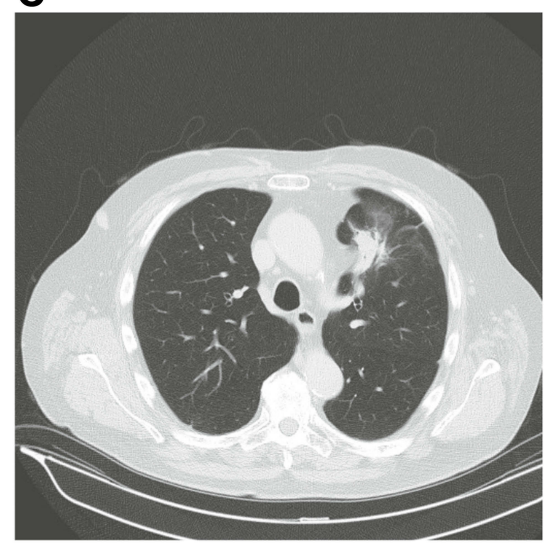

F

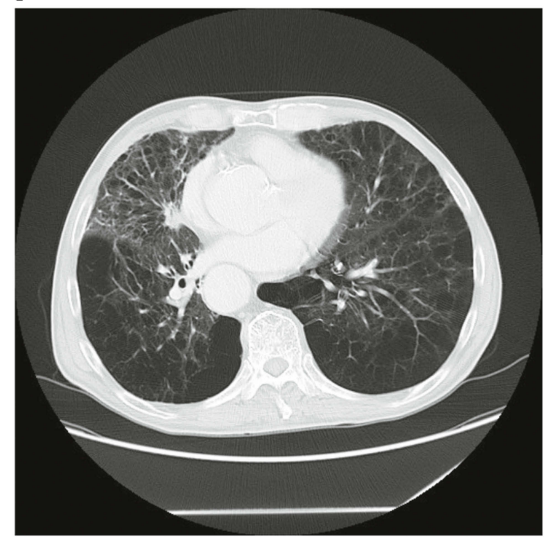

Figure 10 SUVmax persistence associated with local recurrence. (A-C): (A) A 79-year-old patient had a tumour-related finding on a CT (size 18 mm, white arrow). (B) The patient refused histological confirmation and a PET was performed. SUVmax was 7.56. (C) 2 months after SBRT (7.5 Gy in 7 fractions, total dose 52.5 Gy), the size increased $(27 \mathrm{~mm}$ ), and SUVmax raised to 8.01 (images not shown). Tumour progression was histologically confirmed, but the patient refused salvage treatment. (D-H): (D and E) 75-yearold patient with histologically confirmed non-small cell lung cancer. CT (size $24 \mathrm{~mm}$, white arrow) and PET/CT (SUVmax $=13.75)$ at the time of diagnosis. The patient had a severe COPD resp. emphysema. SBRT was done with a dose of $5 \mathrm{~Gy}$ in 10 fractions (total dose $50.0 \mathrm{~Gy}$ ). (F) Tumour response (size $17 \mathrm{~mm}$ ), no evidence of RP. (G) 6 months after SBRT, new tumour growth $(30 \mathrm{~mm}$, white arrow) was detected and histologically confirmed. $(\mathbf{H}) \mathrm{PET} / \mathrm{CT}$ for treatment planning was done $(\mathrm{SUVmax}=\mathrm{I} 8.3 \mathrm{I})$. SUVmax failed to decline. Salvage-treatment was done.

prediction was tested ${ }^{36}$ with a patient database previously used. ${ }^{29}$ The longest axial diameter (RECIST) of the consolidative region was manually measured and the periconsolidative region was automatically calculated and delineated by adding a margin of $16 \mathrm{~mm}$ to the axial diameter. For control, manual delineation of the GGO was done. As a result, 
Table 2 Modified Classification of Early Radiological Changes After SBRT

\begin{tabular}{|l|l|}
\hline Name & Description \\
\hline $\begin{array}{l}\text { Diffuse } \\
\text { consolidation }\end{array}$ & $\begin{array}{l}\text { Consolidation more than } 5 \mathrm{~cm} \text { in largest dimension. } \\
\text { The involved region contains more consolidation } \\
\text { than aerated lung } \\
\text { Consolidation less than } 5 \mathrm{~cm} \text { in largest dimension } \\
\text { consolidation } \\
\text { aiffuse GGO the involved region contains less } \\
\text { consolidation than aerated lung } \\
\text { More than } 5 \mathrm{~cm} \text { of GGO, (without consolidation). } \\
\text { Patchy GGO involved region contains more GGO than } \\
\text { normal lung, } \\
\text { Less than } 5 \mathrm{~cm} \text { of GGO, (without consolidation), } \\
\text { and/or the involved region contains less GGO than } \\
\text { normal lung } \\
\text { No new abnormalities. Includes patients with } \\
\text { tumours that are stable, regressing or resolved, or } \\
\text { fibrosis in the position of the original tumour that is } \\
\text { not larger than the original tumour }\end{array}$ \\
\hline
\end{tabular}

Notes: Data from Palma et al ${ }^{21}$ and Dahele et al. ${ }^{17}$

the semiautomatic algorithm was not inferior to manually delineation, with low interoperator variability and a trend to yield better accuracy. The ongoing study ${ }^{39}$ tested the accuracy with more patients (45 patients, local recurrence: $n=15$, benign changes: $n=30$, see ${ }^{17,30}$ ) and a larger radiomic feature set ( 22 first-order features and 22 second-order features). The physicians assessed post-treatment CT scans and were asked to decide whether a scan was suspect for recurrence or not. Median time to the first detection of recurrence was 15.5 months with a moderate level of agreement across the observers, mean error was $35 \%$, false positive rate $1 \%$ and false negative rate $99 \%$. Within 6 months after SBRT, the physicians were unable to detect recurrences. By contrast, the algorithm demonstrated good performance with a mean error of $24 \%$, a false positive rate of $24 \%$ and a false negative rate of $23 \%$. Within 6 months, radiomic assessment using a semiautomatic algorithm demonstrates excellent results, and this is superior to the physicians' ability to distinguish local relapse or pneumonitis.

\section{Imaging Features from Pre-Treatment Planning CT and Post-Treatment First Follow-Up CT at 3 Months Correlate with Outcome}

Other authors suggested a prognostic model based on a pre-treatment $^{40}$ or post-treatment CT-scan at 3 months, ${ }^{41}$ which includes clinical data (like TNM-Stage or ECOG performance status), manually scored 2D semantic features (like pleural retraction or longest axial diameter) and comprehensive computer-derived 3D radiomic features. Dependent on their individual risk score, patients had either a high or low risk of recurrence. Recent studies validated that radiomics-based pretreatment CT analysis ${ }^{42-45}$ or PET/CT analysis ${ }^{46}$ correlates with overall survival (OS) and local control (LC) respectively, local recurrence. Similar, CT-based radiomics analysis correlates with radiation pneumonitis. ${ }^{47}$ All in all, radiomics is an emerging feature for predicting outcome after SBRT, but due to different use of first- and secondorder features as well as the lack of standardized protocols, routine use in clinical practice remains difficult.

\section{Impact of I 8-FDG-PET/CT Findings}

The maximum standard uptake value (SUVmax) of 18fluorodeoxyglucose (18-FDG) is a measure for tumour glucose metabolism (Figures 5, 6, 8, 9B, G, and 10B, E) and it might correlate with prognostic features, ${ }^{48}$ but an elevated FDG-uptake value is also associated with an inflammation like RP (Figure $8 \mathrm{E}){ }^{49}$ In clinical practice lung cancer diagnosis is based on a CT scan of the chest (Figures 5A, 6A, 7A, G, 8A, 9A, F, and $10 \mathrm{~A}, \mathrm{D})$, ideally proven by a biopsy, and a PET/CT is more accurate than a CT for mediastinal lymph node staging ${ }^{50}$ and it is useful for treatment planning (Figures $5 \mathrm{~B}, \mathrm{D}$ and $6 \mathrm{~B}, \mathrm{D}){ }^{51}$ Therefore, the staging of lung cancer should include PET/CT. ${ }^{52}$ Otherwise, a PET/CT can help if a diagnosis of lung cancer is uncertain, especially in cases in which biopsy is not feasible due to poor constitution of the patient (Figure 6A and B). ${ }^{53}$ After treatment, response assessment is performed using CT and RECIST criteria, ${ }^{49}$ and a PET/CT is recommended once recurrence is suspected on a follow-up CT scan (Figures 9C, D, H, I, and $10 \mathrm{G}, \mathrm{H}) .{ }^{53}$ Over the last decade, several studies investigated the use of 18-FDG-PET/CT in terms of predicting tumour response, overall survival, recurrence and pulmonary toxicities like radiation pneumonitis. $^{8}$

\section{Relevance of Pre-Treatment SUVmax}

Several studies correlated pre-treatment SUVmax (Table 3) with overall survival or local control rates. Some studies found a significant correlation, ${ }^{48,54-58}$ but other studies did not. ${ }^{52,59-61}$ It isnoteworthythatthereportedthresholdofSUVmaxforpredicting OS or LC differs among the studies. Two meta-analyses 8,62 revealed that patients with high levels of pre-treatment SUVmax hadworseoverallsurvival $(\mathrm{p}<0.001)$ andworselocalcontrolrates $(\mathrm{p}<0.001)$, buttheprognosticvalueremainsheterogeneousdueto unknownoptimalSUVmax threshold. ${ }^{63}$ 
Table 3 Selected Studies Reporting on Pre-Treatment or Post-Treatment SUVmax

\begin{tabular}{|c|c|}
\hline Study & Main Findings \\
\hline \multicolumn{2}{|c|}{ Pre-Treatment SUVmax } \\
\hline Hoopes et $\mathrm{al}^{52}$ & $\begin{array}{l}\text { Pre-SUVmax not correlated with OS or LC } \\
\text { hypermetabolic activity may persist } 2 \text { years without recurrence }\end{array}$ \\
\hline Burdick et $a^{59}$ & Pre-SUVmax not correlated with OS \\
\hline Takeda et $\mathrm{al}^{54}$ & $\begin{array}{l}\text { Pre-SUVmax correlated with LC } \\
\text { threshold: pre-SUVmax }=6(\mathrm{p}<0.0 \mathrm{I})\end{array}$ \\
\hline Satoh et al ${ }^{60}$ & Pre-SUVmax not correlated with OS or LC \\
\hline Clarke et $\mathrm{al}^{55}$ & $\begin{array}{l}\text { Pre-SUVmax correlated with } \mathrm{LC} / \text { recurrence } \\
\text { post-SUVmax correlated with } \mathrm{LC} / \text { recurrence } \\
\text { threshold: pre-SUVmax }=5(p=0.0002) \text { resp. post-SUVmax }=2\end{array}$ \\
\hline Vu et $\mathrm{al}^{61}$ & Pre-SUVmax not correlated with OS or LC/recurrence \\
\hline Takeda et $\mathrm{al}^{56}$ & $\begin{array}{l}\text { Pre-SUVmax correlated with OS or LC/recurrence } \\
\text { threshold: pre-SUVmax }=2.55(\mathrm{OS}, \mathrm{p}<0.00 \mathrm{I}) \text { resp. } 3.35(\mathrm{LC}, \mathrm{p}<0.00 \mathrm{I})\end{array}$ \\
\hline Kohutek et al ${ }^{48}$ & $\begin{array}{l}\text { Pre-SUVmax correlated with OS or LC } \\
\text { threshold: pre-SUVmax }=3.0(\mathrm{OS}, \mathrm{p}<0.00 \mathrm{I} \text { resp. LC, } \mathrm{p}<0.003 \text { ) }\end{array}$ \\
\hline Tanaka et al $^{57}$ & $\begin{array}{l}\text { Pre-SUVmax correlated with recurrence } \\
\text { threshold: pre-SUVmax }=8.0\end{array}$ \\
\hline Chaudhuri et $\mathrm{a}^{71}$ & Pre-SUV non-irradiated lung predicts radiation pneumonitis \\
\hline Mazzola et al ${ }^{58}$ & $\begin{array}{l}\text { Pre-SUVmax predicts complete response at } 6 \text { months after SBRT } \\
\text { threshold: pre-SUVmax }=5(p<0.00 \mathrm{I})\end{array}$ \\
\hline Pierson et $\mathrm{al}^{63}$ & Pre-SUVmax not correlated with outcome \\
\hline \multicolumn{2}{|c|}{ Post-Treatment SUVmax } \\
\hline Matsuo et al ${ }^{66}$ & Post-SUVmax within 6 months tends to be high without indicating recurrence \\
\hline Henderson et $\mathrm{al}^{67}$ & $\begin{array}{l}\text { Post-SUVmax at } 12 \text { months is slightly elevated without evidence of recurrence } \\
\text { median post-SUVmax }=6.04 \text { (at } 2 \text { weeks) resp. } 2.80 \text { (at } 26 \text { weeks) } \\
\text { low pre-SUVmax might increase after SBRT within } 2 \text { weeks } \\
\text { high pre-SUVmax commonly declines within } 2 \text { weeks after SBRT }\end{array}$ \\
\hline Dahele et $\mathrm{al}^{65}$ & Post-SUVmax reduction of 3.6 (relative 64\%) correlates with tumor response \\
\hline Bollineni et a ${ }^{49}$ & $\begin{array}{l}\text { Post-SUVmax (at } 3 \text { months) correlated with LC } \\
\text { threshold: post-SUVmax }=5.0(p=0.02)\end{array}$ \\
\hline Takeda et $\mathrm{al}^{68}$ & $\begin{array}{l}\text { Post-SUVmax (at I } 2 \text { months) correlated with LC } \\
\text { threshold: post-SUVmax }=3.2 \text { (early image*) resp. } 4.2 \text { (delayed image*) }\end{array}$ \\
\hline Essler et al ${ }^{69}$ & $\begin{array}{l}\text { Post-SUVmax (at I } 2 \text { months) correlated with LC } \\
\text { threshold: post-SUVmax }=5.48(p=0.009)\end{array}$ \\
\hline Tyran et al ${ }^{64}$ & $\begin{array}{l}\text { Post-SUVmax (at } 3 \text { months) correlated with LC } \\
\text { no threshold found }\end{array}$ \\
\hline Pierson et $\mathrm{al}^{63}$ & Post-SUVmax not correlated with outcome \\
\hline
\end{tabular}

Notes: *Dual-time-point: image registration 60 mins (early) and 120 mins (delayed) after injection of I8-FDG.

Abbreviations: SUV, standard uptake value; OS, overall survival; LC, local control; pre-SUVmax, pre-treatment SUVmax; post-SUVmax, posttreatment SUVmax. 


\section{Relevance of Post-Treatment SUVmax}

Early post-treatment SUVmax (Table 3) at 3 months was investigated. SUVmax seems to be associated with local control resp. local recurrence. ${ }^{49,64}$ For example, Huang et al ${ }^{20,30}$ suggested an imaging follow-up algorithm that recommends salvage therapy if SUVmax is greater than five. A decrease of SUVmax is associated with tumour response (Figure 9B, E, G, and I), ${ }^{65}$ but elevated SUV values might persist after SBRT without evidence for local recurrence (Figure 8E). ${ }^{66,67}$ Furthermore, late post-treatment SUVmax (Table 3) at 12 months was associated with local control, ${ }^{68-70}$ but hypermetabolic activity might persist without evidence of a recurrent tumour. ${ }^{52}$ Once again, the reported thresholds are varying. ${ }^{63}$

\section{Relevance of PET/CT for Predicting Radiation Pneumonitis}

We found only one study correlating pre-treatment SUV in the non-target lung with the risk of symptomatic radiation pneumonitis following SBRT. ${ }^{71}$ Twenty-eight patients with symptomatic RP (grade $\geq 2$, CTCAE 4.03) and 57 without RP (grade 0-1) were compared. Non-target volume was defined as "total lung volume minus PTV" (total nontarget lung volume), respectively, "ipsilateral lung volume minus PTV" (ipsilateral non-target lung volume). Mean lung dose (MLD) and SUV were significantly associated with the risk of developing symptomatic RP, and a model for risk stratification was proposed. Thus, SUV of nontarget lung might be predictive for radiation pneumonitis.

\section{Relevance of Metabolic Tumour Volume (MTV) and Total Lesion Glycolysis (TLG) for Predicting Radiation Pneumonitis}

SUVmax is a histogram-based parameter which measures the hottest voxel in a region of interest, for example, within the region of a tumour, but it is does not correlate with its size. Thus, some authors argue that volume-based parameters like MTV and TLG might better correlate with overall survival or local control than SUVmax. The metabolic tumour volume (MTV) is the total lung volume with an SUV greater than 2.5, defined as the sum of voxels with $\mathrm{SUV}>2.5$, whereas the total lesion glycolysis (TLG) is the product of MTV and SUVmean. ${ }^{72}$ Indeed, Takahashi et $\mathrm{al}^{73}$ and Dosani et $\mathrm{al}^{74}$ found that MTV and TLG are predictive for overall survival and local control, but in contrast, other studies ${ }^{58,75}$ found no correlation. Intriguingly, Mazzola et $\mathrm{al}^{58}$ found an increase of MTV over time. This may correlate with the inflammation of the lung parenchyma after SBRT. In conclusion, predicting tumour control is ambiguous, but MTV might be predictive for radiation pneumonitis.

\section{Limitations of PET/CT}

National guidelines recommend a PET/CT for tumour staging (for example, the United States NCCN guideline or the German S3-guideline of non-small-lung-cancer) since elevated SUVmax is suspect of malignity. PET/CT for predicting radiation pneumonitis after conventional radiotherapy is well investigated, $^{71}$ and PET/CT might be useful for response assessment following SBRT, but some limitations must be discussed. SUVmax associated with local recurrence may fail to decline (Figure 10H), ${ }^{20}$ but high post-treatment SUVmax (mean SUVmax $=4.9$ at 6 months) without evidence of recurrence (Figure $8 \mathrm{E}$ ) was reported, ${ }^{66}$ and metabolic activity (range SUVmax 2.5-5.07) might persist (Figure 9I). ${ }^{52}$ Furthermore, transient increase due to radiation pneumonitis which disappeared after complete remission was also reported. ${ }^{20}$ Thus, elevated post-SBRT SUVmax should not be considered for local treatment failure. ${ }^{67}$ Otherwise, if a follow-up CT-scan (Figure 9C) is suspicious for recurrence and post-SBRT SUVmax is greater than 5 (Figure 9D), ${ }^{30}$ respectively, pretreatment SUVmax was low and post-SBRT SUVmax is less than five, ${ }^{20}$ a recurrent tumour could be considered. ${ }^{20,30}$ Moreover, pre- or post-treatment SUVmax might be correlated with overall survival and local tumour control, but the reported thresholds of SUVmax differ among the studies. That is why some authors argue to interpret PET imaging findings for 2 years after SBRT carefully, ${ }^{64}$ and a follow-up PET/CT is not recommended for response assessment. ${ }^{53}$ One major reason for these differences might be the lack of standardization of obtaining the SUVmax. ${ }^{63}$ The studies ${ }^{48,49,52,54-60,65-67}$ reported several PET-protocols with regard to the use of different PET-scanner, fasting time before injection of 18-FDG (4-6 hrs), blood sugar concentration $(<140-<200 \mathrm{mg} / \mathrm{dl})$, activity of 18 -FDG (3-6 MBq) and waiting time between injection and image registration (40-60 mins). The result is poor agreement between the studies. ${ }^{76}$

\section{Impact of Dosimetric Factors for Predicting Radiation Pneumonitis BED Greater Than 100 Archives Local Control}

Among others, the therapy planning has two goals. On the one hand, the prescribed dose should cover the planning target volume (PTV), on the other hand, the dose 
constraints of the organs at risk (OAR) should be respected. To compare different dose schedules, the biologically effective dose (BED) based on the linear quadratic model is used. ${ }^{77}$ Although this model might be inappropriate in radiosurgery, ${ }^{78}$ a $\mathrm{BED}\left(\alpha / \beta\right.$-ratio $\left.=10, \mathrm{BED}_{10}\right)$ higher than 100 Gy prescribed to the encompassing isodose is recommended in several national guidelines ${ }^{77,79}$ to archive local tumour control. In most studies, the majority of patients were treated with a $\mathrm{BED}_{10}>100 \mathrm{~Gy}^{79}$ resulting in good local control.

\section{Dosimetric Factors Predicting Radiation Pneumonitis After SBRT}

The tissue and organs have different tolerance towards radiation-induced injury. Beside the PTV, a biologically based classification system was suggested which defines the deterministic risk volume (DRV) and the stochastic risk volume (SRV). The DRV is exposed to doses which exceed a specific tolerance to radiotherapy without resulting in compulsory side effects. These are the organs at risk. Above a specific dose threshold, side effects develop, and the extent of damage increases with increasing doses. In the SRV, a specific threshold does not exist, and a minimal dose might result in side effects. The damage probability increases with the doses, mainly resulting in tumour induction. ${ }^{24}$ By optimizing the treatment plan, side effects can be minimized. Several studies (Table 4) attempted to find risk factors for predicting symptomatic radiation pneumonitis (grade $\geq 2$, CTCAE) with focus on volume and dose of SBRT like the PTV, MLD (mean lung dose) or V20 (percentage of lung volume exceeding $20 \mathrm{~Gy}$ ). Age, gender, tumour location and dose scheme do not correlate with radiation pneumonitis, ${ }^{6,80-82}$ confirmed by a pooled analysis of the literature. ${ }^{83}$ Regarding the dosimetric factors, the results are controversial. The studies (Table 4) reported variable correlations between the risk of RP and several dosimetric factors. The pooled analysis ${ }^{83}$ showed that MLD and V20 were significantly correlated with the risk of RP, but the study group failed to ascertain specific dose constraints. The underlying causes could be differences in target definition (like planning target volume) or lung volume definition (whole or ipsilateral lung volume) and the use of different algorithm for dose calculation. ${ }^{83}$ Furthermore, using different number of fractions and dose, one would expect different biological effects, ${ }^{83}$ although the dose scheme was not correlated with RP. ${ }^{82}$ A metaanalysis ${ }^{16}$ could show a relationship between the dosimetric factors and symptomatic RP, and several dose constraints were reported, but the authors suggest to conduct more studies for clarification. However, it is worth mentioning that a 4D-CT for treatment planning, ${ }^{82}$ cone beam CT, realtime tumour tracking ${ }^{84}$ and respiratory gating ${ }^{85}$ might reduce the risk of severe RP. In conclusion, different dose schemes gain comparable local control rates, and dosimetric factors with focus on volume and dose are predictive for RP, but specific dose constraints are lacking, and further studies are needed to clarify.

\section{Impact of Patient-Based Specific Risk Factors Clinical Parameters}

As reported above, age, gender and the location of the tumour (central or peripheral, upper or lower lung) are usually not associated with an increased risk of radiation pneumonitis. The concurrent use of angiotensin-converting enzyme inhibitor might reduce the risk of RP. ${ }^{86,87}$

\section{Tumour Size}

With increasing tumour size, the lung volume receiving low doses extends. Thus, it is expected that larger tumours are associated with worse local control and higher incidences of severe radiation pneumonitis. ${ }^{88}$ However, the literature is controversial. Tumours above $5 \mathrm{~cm}^{\text {diameter }}{ }^{7}$ had a lower 1-year local control rate ( $>5 \mathrm{~cm} 79.8 \%$ vs $<5 \mathrm{~cm} \mathrm{98.2 \% ,}=0.01$ ), but other studies 89,90 suggested similar local control rates using the same threshold. Similarly some studies correlated radiation pneumonitis with $\mathrm{T}$-stage $(\mathrm{p}=0.031)$, respectively, tumour size, ${ }^{6}$ albeit other studies found no correlation. ${ }^{7}$

\section{Pre-Existing Pulmonary Injury and Serum KL-6 Level}

Chronic obstructive pulmonary disease (COPD) is not correlated with RP (Figure 10D), and SBRT might be a treatment option for operable patients with higher risk for pulmonary toxicity following surgery. ${ }^{91}$ Patients with interstitial lung changes (IC) have a higher risk for idiopathic pulmonary fibrosis (one of the seven idiopathic interstitial pneumonias) as IC is one of the major criteria for diagnosis (American Thoracic Society and European Respiratory Society 2002). Thus, patients with IC might have a higher risk for RP following SBRT. Indeed, Yamashita et $\mathrm{al}^{92}$ reported a high incidence of severe RP (grade $\geq 4$ ) in patients with IC ( $p<$ 0.0001 ) and high levels of KL-6 (Krebs von den Lungen-6, $\mathrm{p}<0.0001)$. KL-6 is a glycoprotein which is indicative of 
Table 4 Selected Studies Reporting on Dosimetric Factors for Predicting Symptomatic Radiation Pneumonitis

\begin{tabular}{|c|c|c|c|c|c|}
\hline Study & PTV & MLD & V20 & CTCAE Grade & $\begin{array}{l}\text { Incidence, Median Time to } \\
\text { Onset of RP }\end{array}$ \\
\hline $\begin{array}{l}\text { Guckenberger et al }{ }^{80} \\
\text { no specific threshold }\end{array}$ & $\begin{array}{l}(+) \\
p=0.02^{a}\end{array}$ & $\begin{array}{l}(+) \\
\mathrm{P}<0.05^{\mathrm{a}} \text { (IL) }\end{array}$ & $\begin{array}{l}(+) \\
p<0.05^{\mathrm{a}}\end{array}$ & $\geq^{\circ} 2$ & $\begin{array}{l}{ }^{\circ} 0-1: 81.3 \% \\
{ }^{\circ} 2: 16 \% \\
\text { median time } 5 \text { months }\end{array}$ \\
\hline $\begin{array}{l}\text { Takeda et al }{ }^{81} \\
\text { no specific threshold }\end{array}$ & $\begin{array}{l}(-) \\
p=0.84^{a}\end{array}$ & $\begin{array}{l}(-) \\
\mathrm{P}=0.8 \mathrm{I}^{\mathrm{a}}(\mathrm{TL})\end{array}$ & $\begin{array}{l}(-) \\
p=0.49^{a}\end{array}$ & ${ }^{\circ} 0-2$ vs ${ }^{\circ} 3$ & $\begin{array}{l}{ }^{\circ} 0-\mathrm{I}: 79 \%\left({ }^{\circ} 0: 27.2 \%,{ }^{\circ} \mathrm{I}: 5 \mathrm{I} .8 \%\right) \\
{ }^{\circ} 2: 15.8 \% \\
{ }^{\circ} 3: 5.2 \% \\
\text { median time } 4.3 \text { months }\left({ }^{\circ} \mathrm{I}-2\right) \text { and } 2.2 \\
\text { months }\left({ }^{\circ} 3\right)\end{array}$ \\
\hline $\begin{array}{l}\text { Matsuo et } \mathrm{al}^{98} \\
\text { Threshold PTV: } 37.7 \mathrm{~mL} \\
\left(1 \mathrm{I} .1 \% \text { vs } 34.5 \% \text { for } \geq 2^{\circ}\right) \\
\text { Threshold } \mathrm{V} 20: 5.8 \%(15 \% \text { vs } \\
\left.42.9 \% \text { for } \geq 2^{\circ}\right)\end{array}$ & $\begin{array}{l}(+) \\
p=0.02^{b}\end{array}$ & $\begin{array}{l}(-) \\
\mathrm{p}=0.1 \mathrm{I}^{\mathrm{b}}(\mathrm{TL})\end{array}$ & $\begin{array}{l}(+) \\
p=0.03^{b}\end{array}$ & ${ }^{\circ} 0-I$ vs $\geq{ }^{\circ} 2$ & $\begin{array}{l}{ }^{\circ} 0-1: 79.7 \% \\
{ }^{\circ} 2: 18.9 \% \\
{ }^{\circ} 3: \text { I. } 4 \% \\
\text { median time } 4.5 \text { months }\left({ }^{\circ} 2-3\right)\end{array}$ \\
\hline $\begin{array}{l}\text { Barriger et al }{ }^{99} \\
\text { Threshold MLD: } 4 \text { Gy }(4.3 \% \\
\left.\text { vs } 17.6 \% \text { for } \geq{ }^{\circ} 2\right) \\
\text { Threshold V20: } 4 \%(4.3 \% \text { vs } \\
\left.16.4 \% \text { for } \geq 2^{\circ}\right)\end{array}$ & $\begin{array}{l}(-) \\
p=0.18^{b}\end{array}$ & $\begin{array}{l}(+) \\
\mathrm{p}=0.02^{\mathrm{b}}(\mathrm{TL})\end{array}$ & $\begin{array}{l}(+) \\
p=0.03^{b}\end{array}$ & ${ }^{\circ} 0-I$ vs $\geq{ }^{\circ} 2$ & $\begin{array}{l}{ }^{\circ} 0-\mathrm{I}: 90.8 \%\left({ }^{\circ} 0: 83.2 \%,{ }^{\circ} \mathrm{I}: 7.6 \%\right) \\
{ }^{\circ} 2: 6.8 \% \\
{ }^{\circ} 3: 2.0 \% \\
{ }^{\circ} 4: 0.4 \% \\
\text { median time } 8.4 \text { months }\left({ }^{\circ} \mathrm{I}\right) \text { and } 3.5 \\
\text { months }\left({ }^{\circ} 2-4\right)\end{array}$ \\
\hline $\begin{array}{l}\text { Bongers et al }{ }^{100} \\
\text { Threshold MLD: } 3.6 \mathrm{~Gy}\end{array}$ & n.r. & $\begin{array}{l}(+) \\
\mathrm{p}=0.006^{\mathrm{a}}(\mathrm{CL}) \\
\mathrm{p}=0.02^{\mathrm{a}}(\mathrm{TL})\end{array}$ & n.r. & ${ }^{\circ} 0-2$ vs $\geq^{\circ} 3$ & $\begin{array}{l}{ }^{\circ} 3: 10 \% \\
\text { median time } 6 \text { months }\left({ }^{\circ} 3\right)\end{array}$ \\
\hline $\begin{array}{l}\text { Kanemoto et al }{ }^{6} \\
\text { no specific threshold }\end{array}$ & $\begin{array}{l}(+) \\
p=0.037^{a}\end{array}$ & n.r. & $\begin{array}{l}(+) \\
p=0.02^{\mathrm{a}}\end{array}$ & ${ }^{\circ} 0-1$ vs $\geq{ }^{\circ} 2$ & $\begin{array}{l}{ }^{\circ} 0-1: 87.0 \%\left({ }^{\circ} 0: 21.2 \%,{ }^{\circ} \mathrm{I}: 65.8 \%\right) \\
{ }^{\circ} 2: 11.3 \% \\
{ }^{\circ} 3: 1.7 \% \\
\text { median time } 4.2 \text { months }\left({ }^{\circ} \mathrm{I}\right) \text { and } 2.5 \\
\text { months }\left({ }^{\circ} 2-3\right)\end{array}$ \\
\hline $\begin{array}{l}\text { Kim et al }{ }^{82} \\
\text { Threshold PTV: } 14.35 \mathrm{~mL} \\
\left(8.6 \% \text { vs } 27.0 \% \text { for } \geq^{\circ} 2\right)\end{array}$ & $\begin{array}{l}(+) \\
p=0.042^{b}\end{array}$ & $\begin{array}{l}(-) \\
p=0.54 I^{b}(T L)\end{array}$ & $\begin{array}{l}(-) \\
P=0.222^{b}\end{array}$ & ${ }^{\circ} 0-1$ vs $\geq{ }^{\circ} 2$ & $\begin{array}{l}{ }^{\circ} 0-1: 81.9 \% \\
{ }^{\circ} 2: 15.3 \% \\
{ }^{\circ} 3: 2.8 \% \\
\text { median time } 3.5 \text { months }\left({ }^{\circ} 2-3\right)\end{array}$ \\
\hline $\begin{array}{l}\text { Parker et } \mathrm{al}^{7} \\
\text { Threshold TL MLD: } 5 . \mathrm{I} \text { Gy } \\
\left(6.1 \% \text { vs } 26.9 \% \text { for } \geq{ }^{\circ} 2\right) \\
\text { Threshold TL V20: } 6.7 \%(5.6 \% \\
\left.\text { vs } 25.8 \% \text { for } \geq{ }^{\circ} 2\right) \\
\text { Threshold IL MLD: } 8.6 \text { Gy } \\
\left(5.6 \% \text { vs } 26.7 \% \text { for } \geq{ }^{\circ} 2\right) \\
\text { Threshold IL V20: } 14.9 \% \\
\left(5.6 \% \text { vs } 27.6 \% \geq{ }^{\circ} 2\right)\end{array}$ & $\begin{array}{l}(-) \\
p=0.37^{a}\end{array}$ & $\begin{array}{l}(+) \\
\mathrm{P}=0.02^{\mathrm{a}}(\mathrm{TL}) \\
\mathrm{P}<0.0 \mathrm{I}^{\mathrm{a}}(\mathrm{IL})\end{array}$ & $\begin{array}{l}(+) \\
P=0.02^{a}(T L) \\
P=0.01^{a}(I L)\end{array}$ & ${ }^{\circ} 0-1$ vs $\geq{ }^{\circ} 2$ & $\begin{array}{l}{ }^{\circ} 0 \text {-I: } 90.8 \%\left({ }^{\circ} 0: 43.4 \%,{ }^{\circ} \mathrm{I}: 47.4 \%\right) \\
{ }^{\circ} 2: 6.9 \% \\
{ }^{\circ} 3: 2.3 \% \\
\text { median time } 3.5 \text { months }\left({ }^{\circ} 2-3\right)\end{array}$ \\
\hline
\end{tabular}

Notes: (+) significant, (-) not significant, ${ }^{\mathrm{a}} \mathrm{P}$ value based on comparison of the CTCAE-groups (column 5), ${ }^{\mathrm{b}} \mathrm{P}$ value based on the reported threshold (column I). Abbreviations: n.r., not reported; TL, total lung; IL, ipsilateral lung; $C L$, contralateral lung; RP, radiation pneumonitis.

interstitial pneumonia. Raised serum levels are found in cases with activated interstitial pneumonia. ${ }^{18}$ Subsequent studies ${ }^{93}$ suggested that patients with IC were at higher risk for RP, and this was correlated with worse overall survival.
Dosimetric factors of the IC-patients were not different from those of the non-IC-patients (nIC, $\mathrm{p}>0.1$ ). Yoshitake et $\mathrm{a}^{94}$ validated these results: The cumulative incidence of RP (grade $\geq 2$ ) at 6 months was $44.4 \%$ compared to $4.1 \%$ in 
patients without IC $(\mathrm{p}<0.0001)$. Overall survival at 2 years was worse (IC-patients: $49.6 \%$ vs nIC-patients: $86.7 \%$, p = 0.0005). IC-patients had higher levels of KL-6 $(p<0.001)$, and dosimetric factors were not significantly different between the two groups (MLD p $=0.571$ and V20 $\mathrm{p}=0.698)$. However, patients had a significant higher risk of RP when KL-6 was greater $600 \mathrm{U} / \mathrm{mL}$ (IC: $83.5 \%$ vs nIC: $25.0 \%, \mathrm{p}=0.017)$ and when MLD was greater $4 \mathrm{~Gy}(70 \%$ vs $12.5 \%, \mathrm{p}=0.038)$. V20 did not correlate with an increased risk of RP $(\mathrm{p}=0.210) .{ }^{94}$ In conclusion, patients with high levels of KL-6 and interstitial changes may develop severe radiation pneumonitis. They should not receive SBRT, ${ }^{18}$ and if not possible, these patients should be carefully monitored after SBRT. ${ }^{95}$ Detection of interstitial changes can avoid lethal radiation pneumonitis (grade 5). ${ }^{91}$

\section{Conclusions}

Radiation pneumonitis (Figures 1-3) is one of the most common toxicities following SBRT for lung cancer, and more than $50 \%$ of the patients have corresponding radiological findings, but they are usually asymptomatic. By contrast, local recurrence is less common as local control rates are good (Figures 4 and 5). Nevertheless, distinguishing radiation pneumonitis (Figures 7-9) from early local recurrence (Figure 10) is challenging. In particular, Figure 9 shows that a CT with findings suspect of a recurrent tumour is not necessarily associated with relapse. Promising data were reported by Mattonen et al. They established a semiautomatic algorithm for distinguishing local recurrence from benign CT changes within 6 months. The use of radiomics improved the results, but since standard proceeding protocols are lacking, the routine use in clinical practice remains difficult. Furthermore, various studies investigated the utility of SUVmax. In general, PET/CT is useful for tumour detection (Figure 6) and higher values of SUVmax are associated with worse local control, but elevated values of SUVmax following SBRT are correlated with recurrence (Figure 10) as well as with radiation pneumonitis (Figure 8). Due to the lack of standardization of PET-CT-scans, an optimal threshold of SUVmax could not be found yet. Since SBRT induces vascular damage in addition to DNAdouble-strand breakages, ${ }^{96}$ some authors argued to use hybrid PET and CT perfusion imaging. ${ }^{3,97}$ CT perfusion imaging is a dynamic contrast-enhanced CT technique which correlates with tumour angiogenesis and microvessel density $^{97}$ and may observe the destruction of blood vessels. ${ }^{3}$ Unfortunately, studies are rare. Dosimetric factors might be better to avoid radiation pneumonitis or recurrence.
Optimizing the treatment plan, the risk of radiation pneumonitis might be reduced, and at the same time, good local tumour control can be achieved, but specific dose constraints are missing. One major problem is the retrospective nature of the reported studies and the used patient database. Histological verification of tumour is inconsistent, and definition of tumour recurrence varies among the reported studies. This might result in selection bias. In summary, we found promising data to predict local recurrence or radiation pneumonitis, but this data remains controversial. This underlines the need for prospective randomized trials. Ongoing studies might improve the reported findings. However, radiation pneumonitis is common, and local recurrence is rare. For decision-making, patients who are suspected of a recurrent tumour should be introduced at the interdisciplinary tumour conference, which should be attended by radiologists and surgeons as well as haematology oncologists and radio oncologists.

\section{Acknowledgment}

Special thanks to Mr. Peter Carr, Birmingham University Hospital, for proofreading our manuscript.

\section{Disclosure}

The authors report no conflicts of interest in this work.

\section{References}

1. Thomas A. Latest global cancer data: cancer burden rises to 18.1 million new cases and 9.6 million cancer deaths in 2018. [Press Release $\mathrm{N}^{\circ}$ 263]. Available from: https://www.iarc.fr/wp-content /uploads/2018/09/pr263_E.pdf. Accessed February 7, 2020.

2. Hirsch FR, Scagliotti GV, Mulshine JL, et al. Lung cancer: current therapies and new targeted treatments. Lancet. 2017;389 (10066):299-311. doi:10.1016/S0140-6736(16)30958-8

3. Yang D-M, Palma D, Louie A, et al. Assessment of tumour response after stereotactic ablative radiation therapy for lung cancer: a prospective quantitative hybrid 18 F-fluorodeoxyglucose-positron emission tomography and CT perfusion study. $J$ Med Imaging Radiat Oncol. 2019;63(1):94-101. doi:10.1111/1754-9485.12807

4. Baumann P, Nyman J, Hoyer M, et al. Outcome in a prospective Phase II trial of medically inoperable stage I non-small-cell lung cancer patients treated with stereotactic body radiotherapy. J Clin Oncol. 2009;27(20):3290-3296. doi:10.1200/JCO.2008.21.5681

5. Timmerman R, Paulus R, Galvin J, et al. Stereotactic body radiation therapy for inoperable early stage lung cancer. JAMA. 2010;303 (11):1070-1076. doi:10.1001/jama.2010.261

6. Kanemoto A, Matsumoto Y, Sugita T. Timing and characteristics of radiation pneumonitis after stereotactic body radiotherapy for peripherally located stage I lung cancer. Int J Clin Oncol. 2015;20 (4):680-685. doi:10.1007/s10147-014-0766-3

7. Parker SM, Siochi RA, Wen S, Mattes MD. Impact of tumor size on local control and pneumonitis after stereotactic body radiation therapy for lung tumors. Pract Radiat Oncol. 2019;9(1):e90-e97. doi:10.1016/ j.prro.2018.09.003 
8. Dong M, Liu J, Sun X, Xing L. Prognostic significance of SUVmax on pretreatment 18 F-FDG PET/CT in early-stage non-small cell lung cancer treated with stereotactic body radiotherapy: a meta-analysis. $J$ Med Imaging Radiat Oncol. 2017;61(5):652-659. doi:10.1111/1754-9485.12599

9. Rieber J, Streblow J, Uhlmann L, et al. Stereotactic body radiotherapy (SBRT) for medically inoperable lung metastases-A pooled analysis of the German working group "stereotactic radiotherapy". Lung Cancer. 2016;97:51-58. doi:10.1016/j.lungcan.2016.04.012

10. Lagerwaard FJ, Verstegen NE, Haasbeek CJA, et al. Outcomes of stereotactic ablative radiotherapy in patients with potentially operable stage I non-small cell lung cancer. Int J Radiat Oncol Biol Phys. 2012;83(1):348-353. doi:10.1016/j.ijrobp.2011.06.2003

11. Chang JY, Senan S, Paul MA, et al. Stereotactic ablative radiotherapy versus lobectomy for operable stage I non-small-cell lung cancer: a pooled analysis of two randomised trials. Lancet Oncol. 2015;16(6):630-637. doi:10.1016/S1470-2045(15)70168-3

12. Ronden MI, Palma D, Slotman BJ, Senan S. Brief report on radiological changes following stereotactic ablative radiotherapy (SABR) for early-stage lung tumors: a pictorial essay. $J$ Thorac Oncol. 2018;13(6):855-862. doi:10.1016/j.jtho.2018.02.023

13. Mattonen SA, Palma DA, Haasbeek CJA, Senan S, Ward AD. Early prediction of tumor recurrence based on CT texture changes after stereotactic ablative radiotherapy (SABR) for lung cancer. Med Phys. 2014;41(3):33502. doi:10.1118/1.4866219

14. Badellino S, Di Muzio J, Schivazappa G, et al. No differences in radiological changes after 3D conformal vs VMAT-based stereotactic radiotherapy for early stage non-small cell lung cancer. $\mathrm{Br}$ J Radiol. 2017;90(1078):20170143. doi:10.1259/bjr.20170143

15. Linda A, Trovo M, Bradley JD. Radiation injury of the lung after stereotactic body radiation therapy (SBRT) for lung cancer: a timeline and pattern of CT changes. Eur J Radiol. 2011;79 (1):147-154. doi:10.1016/j.ejrad.2009.10.029

16. Lu C, Lei $\mathrm{Z}, \mathrm{Wu} \mathrm{H}, \mathrm{Lu} \mathrm{H}$. Evaluating risk factors of radiation pneumonitis after stereotactic body radiation therapy in lung tumor: meta-analysis of 9 observational studies. PLoS One. 2018;13(12): e0208637. doi:10.1371/journal.pone.0208637

17. Dahele M, Palma D, Lagerwaard F, Slotman B, Senan S. Radiological changes after stereotactic radiotherapy for stage I lung cancer. $J$ Thorac Oncol. 2011;6(7):1221-1228. doi:10.1097/JTO.0b013e318219aac5

18. Yamashita H, Takahashi W, Haga A, Nakagawa K. Radiation pneumonitis after stereotactic radiation therapy for lung cancer. World J Radiol. 2014;6(9):708-715. doi:10.4329/wjr.v6.i9.708

19. Frakulli R, Salvi F, Balestrini D, et al. Radiological differential diagnosis between fibrosis and recurrence after stereotactic body radiation therapy (SBRT) in early stage non-small cell lung cancer (NSCLC). Transl Lung Cancer Res. 2017;6(Suppl 1):S1-S7. doi:10.21037/tlcr.2017.10.01

20. Huang K, Dahele M, Senan S, et al. Radiographic changes after lung stereotactic ablative radiotherapy (SABR)-can we distinguish recurrence from fibrosis? A systematic review of the literature. Radiother Oncol. 2012;102(3):335-342. doi:10.1016/j.radonc.2011.12.018

21. Palma DA, Senan S, Haasbeek CJA, Verbakel WFAR, Vincent A, Lagerwaard F. Radiological and clinical pneumonitis after stereotactic lung radiotherapy: a matched analysis of three-dimensional conformal and volumetric-modulated arc therapy techniques. Int $J$ Radiat Oncol Biol Phys. 2011;80(2):506-513. doi:10.1016/j.jirobp.2010.02.032

22. Kimura T, Matsuura K, Murakami Y, et al. CT appearance of radiation injury of the lung and clinical symptoms after stereotactic body radiation therapy (SBRT) for lung cancers: are patients with pulmonary emphysema also candidates for SBRT for lung cancers? Int J Radiat Oncol Biol Phys. 2006;66(2):483-491. doi:10.1016/j.jirobp.2006.05.008

23. Knoll MA, Salvatore M, Sheu RD, et al. The use of isodose levels to interpret radiation induced lung injury: a quantitative analysis of computed tomography changes. Quant Imaging Med Surg. 2016;6 (1):35-41. doi:10.3978/j.issn.2223-4292.2016.02.07
24. Hildebrandt G, Hartz JM, Joost S. Strahlenschutz in der Radioonkologie. Strahlenschutz Praxis. 2017;23(4/2017):25-27.

25. Senthi S, Dahele M, van de Ven PM, Slotman BJ, Senan S. Late radiologic changes after stereotactic ablative radiotherapy for early stage lung cancer: a comparison of fixed-beam versus arc delivery techniques. Radiother Oncol. 2013;109(1):77-81. doi:10.1016/j. radonc.2013.08.034

26. Chi A, Liao Z, Nguyen NP, Xu J, Stea B, Komaki R. Systemic review of the patterns of failure following stereotactic body radiation therapy in early-stage non-small-cell lung cancer: clinical implications. Radiother Oncol. 2010;94(1):1-11. doi:10.1016/j.radonc.2009.12.008

27. Senthi S, Lagerwaard FJ, Haasbeek CJA, Slotman BJ, Senan S. Patterns of disease recurrence after stereotactic ablative radiotherapy for early stage non-small-cell lung cancer: a retrospective analysis. Lancet Oncol. 2012;13(8):802-809. doi:10.1016/S1470-2045(12)70242-5

28. Eisenhauer EA, Therasse P, Bogaerts J, et al. New response evaluation criteria in solid tumours: revised RECIST guideline (version 1.1). Eur J Cancer. 2009;45(2):228-247. doi:10.1016/j.ejca.2008.10.026

29. Mattonen SA, Palma DA, Haasbeek CJA, Senan S, Ward AD. Distinguishing radiation fibrosis from tumour recurrence after stereotactic ablative radiotherapy (SABR) for lung cancer: a quantitative analysis of CT density changes. Acta Oncol. 2013;52(5):910-918. doi:10.3109/0284186X.2012.731525

30. Huang K, Senthi S, Palma DA, et al. High-risk CT features for detection of local recurrence after stereotactic ablative radiotherapy for lung cancer. Radiother Oncol. 2013;109(1):51-57. doi:10.1016/ j.radonc.2013.06.047

31. Peulen H, Mantel F, Guckenberger M, et al. Validation of high-risk computed tomography features for detection of local recurrence after stereotactic body radiation therapy for early-stage non-small cell lung cancer. Int $J$ Radiat Oncol Biol Phys. 2016;96 (1):134-141. doi:10.1016/j.jirobp.2016.04.003

32. Palma DA, van Sörnsen de Koste JR, Verbakel WFAR, Senan S. A new approach to quantifying lung damage after stereotactic body radiation therapy. Acta Oncol. 2011;50(4):509-517. doi:10.3109/ 0284186X.2010.541934

33. Gillies RJ, Kinahan PE, Hricak H. Radiomics: images are more than pictures, they are data. Radiology. 2016;278(2):563-577. doi:10.1148/radiol.2015151169

34. Mattonen SA, Ward AD, Palma DA. Pulmonary imaging after stereotactic radiotherapy-does RECIST still apply? Br J Radiol. 2016;89(1065):20160113. doi:10.1259/bjr.20160113

35. Lambin P, Rios-Velazquez E, Leijenaar R, et al. Radiomics: extracting more information from medical images using advanced feature analysis. Eur J Cancer. 2012;48(4):441-446. doi:10.1016/j.ejca.2011.11.036

36. Mattonen SA, Tetar S, Palma DA, Louie AV, Senan S, Ward AD. Imaging texture analysis for automated prediction of lung cancer recurrence after stereotactic radiotherapy. $J$ Med Imaging (Bellingham). 2015;2(4):41010. doi:10.1117/1.JMI.2.4.041010

37. Mattonen SA, Palma DA, Cornelis JA, Haasbeek SS, Ward AD. Early prediction of lung cancer recurrence after stereotactic radiotherapy using second order texture statistics. Med Imaging. 2014;. doi: $10.1117 / 12.2042700$

38. Mattonen SA, Palma DA, Cornelis JA, Haasbeek SS, Ward AD. Texture analysis of automatic graph cuts segmentations for detection of lung cancer recurrence after stereotactic radiotherapy. Med Imaging. 2015; . doi:10.1117/12.2081427

39. Mattonen SA, Palma DA, Johnson C, et al. Detection of local cancer recurrence after stereotactic ablative radiation therapy for lung cancer: physician performance versus radiomic assessment. Int $J$ Radiat Oncol Biol Phys. 2016;94(5):1121-1128. doi:10.1016/j.jirobp.2015.12.369

40. Li Q, Kim J, Balagurunathan Y, et al. Imaging features from pretreatment CT scans are associated with clinical outcomes in nonsmall-cell lung cancer patients treated with stereotactic body radiotherapy. Med Phys. 2017;44(8):4341-4349. doi:10.1002/mp. 12309 
41. Li Q, Kim J, Balagurunathan Y, et al. CT imaging features associated with recurrence in non-small cell lung cancer patients after stereotactic body radiotherapy. Radiat Oncol. 2017;12(1):158. doi:10.1186/s13014-017-0892-y

42. Bousabarah K, Temming S, Hoevels M, et al. Radiomics-Analyse von Planungs-Computertomogrammen zur Vorhersage von strahleninduzierter Lungenschädigung und onkologischem Ergebnis bei Lungenkrebspatienten nach robotischer stereotaktischer Strahlentherapie [Radiomic Analysis of Planning Computed Tomograms for Predicting Radiation-Induced Lung Injury and Outcome in Lung Cancer Patients Treated With Robotic Stereotactic Body Radiation Therapy]. Strahlenther Onkol. 2019. German. doi:10.1007/s00066-019-01452-7

43. Lafata KJ, Hong JC, Geng R, et al. Association of pre-treatment radiomic features with lung cancer recurrence following stereotactic body radiation therapy. Phys Med Biol. 2019;64(2):25007. doi:10.1088/1361-6560/aaf5a5

44. Starkov P, Aguilera TA, Golden DI, et al. The use of texture-based radiomics $\mathrm{CT}$ analysis to predict outcomes in early-stage non-small cell lung cancer treated with stereotactic ablative radiotherapy. $\mathrm{Br}$ J Radiol. 2019;92(1094):20180228. doi:10.1259/bjr.20180228

45. Huynh E, Coroller TP, Narayan V, et al. CT-based radiomic analysis of stereotactic body radiation therapy patients with lung cancer. Radiother Oncol. 2016;120(2):258-266. doi:10.1016/j.radonc.2016.05.024

46. Oikonomou A, Khalvati F, Tyrrell PN, et al. Radiomics analysis at $\mathrm{PET} / \mathrm{CT}$ contributes to prognosis of recurrence and survival in lung cancer treated with stereotactic body radiotherapy. Sci Rep. 2018;8 (1):4003. doi:10.1038/s41598-018-22357-y

47. Moran A, Daly ME, Yip SSF, Yamamoto T. Radiomics-based assessment of radiation-induced lung injury after stereotactic body radiotherapy. Clin Lung Cancer. 2017;18(6):e425-e431. doi:10.1016/ j.cllc.2017.05.014

48. Kohutek ZA, Wu AJ, Zhang Z, et al. FDG-PET maximum standardized uptake value is prognostic for recurrence and survival after stereotactic body radiotherapy for non-small cell lung cancer. Lung Cancer. 2015;89(2):115-120. doi:10.1016/j.lungcan.2015.05.019

49. Bollineni VR, Widder J, Pruim J, Langendijk JA, Wiegman EM. Residual ${ }^{18}$ F-FDG-PET uptake 12 weeks after stereotactic ablative radiotherapy for stage I non-small-cell lung cancer predicts local control. Int $J$ Radiat Oncol Biol Phys. 2012;83(4):e551-5. doi:10.1016/j.ijrobp.2012.01.012

50. Gould MK, Kuschner WG, Rydzak CE, et al. Test performance of positron emission tomography and computed tomography for mediastinal staging in patients with non-small-cell lung cancer: a meta-analysis. Ann Intern Med. 2003;139(11):879-892. doi:10.7326/ 0003-4819-139-11-200311180-00013

51. Rajagopalan MS, Heron DE. Role of PET/CT imaging in stereotactic body radiotherapy. Future Oncol. 2010;6(2):305-317. doi:10.2217/fon.09.166

52. Hoopes DJ, Tann M, Fletcher JW, et al. FDG-PET and stereotactic body radiotherapy (SBRT) for stage I non-small-cell lung cancer. Lung Cancer. 2007;56(2):229-234. doi:10.1016/j.lungcan.2006.12.009

53. Vansteenkiste J, Crinò L, Dooms C, et al. 2nd ESMO Consensus Conference on Lung Cancer: early-stage non-small-cell lung cancer consensus on diagnosis, treatment and follow-up. Ann Oncol. 2014;25(8):1462-1474. doi:10.1093/annonc/mdu089

54. Takeda A, Yokosuka N, Ohashi T, et al. The maximum standardized uptake value (SUVmax) on FDG-PET is a strong predictor of local recurrence for localized non-small-cell lung cancer after stereotactic body radiotherapy (SBRT). Radiother Oncol. 2011;101(2):291-297. doi:10.1016/j.radonc.2011.08.008

55. Clarke K, Taremi M, Dahele $\mathrm{M}$, et al. Stereotactic body radiotherapy (SBRT) for non-small cell lung cancer (NSCLC): is FDG-PET a predictor of outcome? Radiother Oncol. 2012;104 (1):62-66. doi:10.1016/j.radonc.2012.04.019
56. Takeda A, Sanuki N, Fujii H, et al. Maximum standardized uptake value on FDG-PET is a strong predictor of overall and disease-free survival for non-small-cell lung cancer patients after stereotactic body radiotherapy. J Thorac Oncol. 2014;9(1):65-73. doi:10.1097/ JTO.0000000000000031

57. Tanaka H, Hayashi S, Hoshi H. Pretreatment maximum standardized uptake value on $18 \mathrm{~F}$-fluorodeoxyglucose positron emission tomography is a predictor of outcome for stage I non-small cell lung cancer after stereotactic body radiotherapy. Asia Pac J Clin Oncol. 2016;12(1):e113-7. doi:10.1111/ajco.12128

58. Mazzola R, Fiorentino A, Di Paola G, et al. Stereotactic ablative radiation therapy for lung oligometastases: predictive parameters of early response by 18FDG-PET/CT. J Thorac Oncol. 2017;12 (3):547-555. doi:10.1016/j.jtho.2016.11.2234

59. Burdick MJ, Stephans KL, Reddy CA, Djemil T, Srinivas SM, Videtic GMM. Maximum standardized uptake value from staging FDG-PET/CT does not predict treatment outcome for early-stage non-smallcell lung cancer treated with stereotactic body radiotherapy. Int $J$ Radiat Oncol Biol Phys. 2010;78(4):1033-1039. doi:10.1016/j.jprobp.2009.09.081

60. Satoh Y, Nambu A, Onishi H, et al. Value of dual time point F-18 FDG-PET/CT imaging for the evaluation of prognosis and risk factors for recurrence in patients with stage I non-small cell lung cancer treated with stereotactic body radiation therapy. Eur J Radiol. 2012;81(11):3530-3534. doi:10.1016/j.ejrad.2011.11.047

61. Vu CC, Matthews R, Kim B, Franceschi D, Bilfinger TV, Moore WH Prognostic value of metabolic tumor volume and total lesion glycolysis from ${ }^{18}$ F-FDG PET/CT in patients undergoing stereotactic body radiation therapy for stage I non-small-cell lung cancer. Nucl Med Commun. 2013;34(10):959-963. doi:10.1097/MNM.0b013e32836491a9

62. Na F, Wang J, Li C, Deng L, Xue J, Lu Y. Primary tumor standardized uptake value measured on F18-Fluorodeoxyglucose positron emission tomography is of prediction value for survival and local control in non-small-cell lung cancer receiving radiotherapy: meta-analysis. J Thorac Oncol. 2014;9(6):834-842. doi:10.1097/ JTO.0000000000000185

63. Pierson C, Grinchak T, Sokolovic C, et al. Response criteria in solid tumors (PERCIST/RECIST) and SUVmax in early-stage non-small cell lung cancer patients treated with stereotactic body radiotherapy. Radiat Oncol. 2018;13(1):34. doi:10.1186/s13014-018-0980-7

64. Tyran M, Charrier N, Darreon J, Madroszyk A, Tallet A, Salem N. Early PET-CT after stereotactic radiotherapy for stage 1 non-small cell lung carcinoma is predictive of local control. In Vivo. 2018;32 (1):121-124. doi:10.21873/invivo.11213

65. Dahele M, Freeman M, Pearson S, et al. Early metabolic response evaluation after stereotactic radiotherapy for lung cancer: pilot experience with 18F-fluorodeoxyglucose positron emission tomography-computed tomography. Clin Oncol ( $R$ Coll Radiol). 2011;23(5):359-363. doi:10.1016/j.clon.2010.11.009

66. Matsuo Y, Nakamoto Y, Nagata Y, et al. Characterization of FDG-PET images after stereotactic body radiation therapy for lung cancer. Radiother Oncol. 2010;97(2):200-204. doi:10.1016/j. radonc.2010.04.011

67. Henderson MA, Hoopes DJ, Fletcher JW, et al. A pilot trial of serial $18 \mathrm{~F}$-fluorodeoxyglucose positron emission tomography in patients with medically inoperable stage I non-small-cell lung cancer treated with hypofractionated stereotactic body radiotherapy. Int J Radiat Oncol Biol Phys. 2010;76(3):789-795. doi:10.1016/j.ijrobp.2009.02.051

68. Takeda A, Kunieda E, Fujii H, et al. Evaluation for local failure by 18F-FDG PET/CT in comparison with CT findings after stereotactic body radiotherapy (SBRT) for localized non-small-cell lung cancer. Lung Cancer. 2013;79(3):248-253. doi:10.1016/j.lungcan.2012.11.008

69. Essler M, Wantke J, Mayer B, et al. Positron-emission tomography CT to identify local recurrence in stage I lung cancer patients 1 year after stereotactic body radiation therapy. Strahlenther Onkol. 2013;189(6):495-501. doi:10.1007/s00066-013-0310-9 
70. Nakajima N, Sugawara Y, Kataoka M, et al. Differentiation of tumor recurrence from radiation-induced pulmonary fibrosis after stereotactic ablative radiotherapy for lung cancer: characterization of 18F-FDG PET/CT findings. Ann Nucl Med. 2013;27 (3):261-270. doi:10.1007/s12149-012-0682-4

71. Chaudhuri AA, Binkley MS, Rigdon J, et al. Pre-treatment non-target lung FDG-PET uptake predicts symptomatic radiation pneumonitis following Stereotactic Ablative Radiotherapy (SABR). Radiother Oncol. 2016;119 (3):454 460. doi:10.1016/j.radonc.2016.05.007

72. Satoh Y, Onishi H, Nambu A, Araki T. Volume-based parameters measured by using FDG PET/CT in patients with stage I NSCLC treated with stereotactic body radiation therapy: prognostic value. Radiology. 2014;270(1):275-281. doi:10.1148/radiol.13130652

73. Takahashi N, Yamamoto T, Matsushita H, et al. Metabolic tumor volume on FDG-PET/CT is a possible prognostic factor for Stage I lung cancer patients treated with stereotactic body radiation therapy: a retrospective clinical study. $J$ Radiat Res. 2016;57 (6):655-661. doi:10.1093/jrr/rrw048

74. Dosani M, Yang R, McLay M, et al. Metabolic tumour volume is prognostic in patients with non-small-cell lung cancer treated with stereotactic ablative radiotherapy. Curr Oncol. 2019;26(1):e57-e63. doi: $10.3747 /$ co. 26.4167

75. Takeda K, Takanami K, Shirata Y, et al. Clinical utility of texture analysis of 18F-FDG PET/CT in patients with Stage I lung cancer treated with stereotactic body radiotherapy. J Radiat Res. 2017;58 (6):862-869. doi:10.1093/jrr/rrx050

76. Marom EM, Munden RF, Truong MT, et al. Interobserver and intraobserver variability of standardized uptake value measurements in non-small-cell lung cancer. $J$ Thorac Imaging. 2006;21 (3):205-212. doi:10.1097/01.rti.0000213643.49664.4d

77. Loganadane G, Martinetti F, Mercier O, et al. Stereotactic ablative radiotherapy for early stage non-small cell lung cancer: a critical literature review of predictive factors of relapse. Cancer Treat Rev. 2016;50:240-246. doi:10.1016/j.ctrv.2016.10.002

78. Kirkpatrick JP, Meyer JJ, Marks LB. The linear-quadratic model is inappropriate to model high dose per fraction effects in radiosurgery. Semin Radiat Oncol. 2008;18(4):240-243. doi:10.1016/j.semradonc.2008.04.005

79. Prezzano KM, Ma SJ, Hermann GM, Rivers CI, Gomez-Suescun JA, Singh AK. Stereotactic body radiation therapy for non-small cell lung cancer: a review. World J Clin Oncol. 2019;10(1):14-27. doi:10.5306/wjco.v10.i1.14

80. Guckenberger M, Baier K, Polat B, et al. Dose-response relationship for radiation-induced pneumonitis after pulmonary stereotactic body radiotherapy. Radiother Oncol. 2010;97(1):65-70. doi:10.1016/j. radonc. 2010.04.027

81. Takeda A, Ohashi T, Kunieda E, et al. Early graphical appearance of radiation pneumonitis correlates with the severity of radiation pneumonitis after stereotactic body radiotherapy (SBRT) in patients with lung tumors. Int J Radiat Oncol Biol Phys. 2010;77 (3):685-690. doi:10.1016/j.ijrobp.2009.06.001

82. Kim K, Lee J, Cho Y, et al. Predictive factors of symptomatic radiation pneumonitis in primary and metastatic lung tumors treated with stereotactic ablative body radiotherapy. Radiat Oncol J. 2017;35(2):163-171. doi:10.3857/roj.2017.00066

83. Zhao J, Yorke ED, Li L, et al. Simple factors associated with radiation-induced lung toxicity after stereotactic body radiation therapy of the thorax: a pooled analysis of 88 studies. Int $J$ Radiat Oncol Biol Phys. 2016;95(5):1357-1366. doi:10.1016/j.ijrobp.2016.03.024

84. Chapman $\mathrm{CH}$, McGuinness $\mathrm{C}$, Gottschalk AR, et al. Influence of respiratory motion management technique on radiation pneumonitis risk with robotic stereotactic body radiation therapy. J Appl Clin Med Phys. 2018;19(4):48-57. doi:10.1002/acm2.12338
85. Tian S, Switchenko JM, Cassidy RJ, et al. Predictors of pneumonitisfree survival following lung stereotactic body radiation therapy. Transl Lung Cancer Res. 2019;8(1):15-23. doi:10.21037/tlcr.2018.10.11

86. Alite F, Balasubramanian N, Adams W, Surucu M, Mescioglu I, Harkenrider MM. Decreased risk of radiation pneumonitis with coincident concurrent use of angiotensin-converting enzyme inhibitors in patients receiving lung stereotactic body radiation therapy. Am J Clin Oncol. 2018;41(6):576-580. doi:10.1097/COC.0000000000000324

87. Bracci S, Valeriani M, Agolli L, de Sanctis V, Maurizi Enrici R, Osti MF. Renin-angiotensin system inhibitors might help to reduce the development of symptomatic radiation pneumonitis after stereotactic body radiotherapy for lung cancer. Clin Lung Cancer. 2016;17(3):189-197. doi:10.1016/j.cllc.2015.08.007

88. Dunlap NE, Larner JM, Read PW, et al. Size matters: a comparison of T1 and T2 peripheral non-small-cell lung cancers treated with stereotactic body radiation therapy (SBRT). J Thorac Cardiovasc Surg. 2010;140(3):583-589. doi:10.1016/j.jtcvs.2010.01.046

89. Verma V, Shostrom VK, Kumar SS, et al. Multi-institutional experience of stereotactic body radiotherapy for large ( $\geq 5$ centimeters) non-small cell lung tumors. Cancer. 2017;123(4):688-696. doi:10.1002/cncr.30375

90. Peterson J, Niles C, Patel A, et al. Stereotactic body radiotherapy for large $(5 \mathrm{~cm})$ non-small-cell lung cancer. Clin Lung Cancer. 2017;18(4):396-400. doi:10.1016/j.cllc.2016.11.020

91. Doi H, Nakamatsu K, Nishimura Y. Stereotactic body radiotherapy in patients with chronic obstructive pulmonary disease and interstitial pneumonia: a review. Int J Clin Oncol. 2019;24:899-909. doi:10.1007/s10147-019-01432-y

92. Yamashita H, Kobayashi-Shibata S, Terahara A, et al. Prescreening based on the presence of CT-scan abnormalities and biomarkers (KL-6 and SP-D) may reduce severe radiation pneumonitis after stereotactic radiotherapy. Radiat Oncol. 2010;5:32. doi:10.1186/ 1748-717X-5-32

93. Ueki N, Matsuo Y, Togashi Y, et al. Impact of pretreatment interstitial lung disease on radiation pneumonitis and survival after stereotactic body radiation therapy for lung cancer. J Thorac Oncol. 2015;10(1):116-125. doi:10.1097/JTO.0000000000000359

94. Yoshitake T, Shioyama Y, Asai K, et al. Impact of interstitial changes on radiation pneumonitis after stereotactic body radiation therapy for lung cancer. Anticancer Res. 2015;35(9):4909-4913.

95. Okubo M, Itonaga $\mathrm{T}$, Saito $\mathrm{T}$, et al. Predicting risk factors for radiation pneumonitis after stereotactic body radiation therapy for primary or metastatic lung tumours. Br J Radiol. 2017;90 (1073):20160508. doi:10.1259/bjr.20160508

96. Park HJ, Griffin RJ, Hui S, Levitt SH, Song CW. Radiation-induced vascular damage in tumors: implications of vascular damage in ablative hypofractionated radiotherapy (SBRT and SRS). Radiat Res. 2012;177(3):311-327. doi:10.1667/RR2773.1

97. Sawyer B, Pun E, Samuel M, et al. CT perfusion imaging in response assessment of pulmonary metastases undergoing stereotactic ablative radiotherapy. J Med Imaging Radiat Oncol. 2015;59 (2):207-215. doi:10.1111/1754-9485.12272

98. Matsuo Y, Shibuya K, Nakamura M, et al. Dose-volume metrics associated with radiation pneumonitis after stereotactic body radiation therapy for lung cancer. Int J Radiat Oncol Biol Phys. 2012;83 (4):e545-9. doi:10.1016/j.ijrobp.2012.01.018

99. Barriger RB, Forquer JA, Brabham JG, et al. A dose-volume analysis of radiation pneumonitis in non-small cell lung cancer patients treated with stereotactic body radiation therapy. Int J Radiat Oncol Biol Phys. 2012;82(1):457-462. doi:10.1016/j.ijrobp.2010.08.056

100. Bongers EM, Botticella A, Palma DA, et al. Predictive parameters of symptomatic radiation pneumonitis following stereotactic or hypofractionated radiotherapy delivered using volumetric modulated arcs. Radiother Oncol. 2013;109(1):95-99. doi:10.1016/j. radonc.2013.10.011 


\section{Publish your work in this journal}

Reports in Medical Imaging is an international, peer-reviewed, open access journal publishing original research, reports, reviews and commentaries on all areas of medical imaging. The manuscript management system is completely online and includes a very quick and fair peerreview system, which is all easy to use. Visit http://www.dovepress. com/testimonials.php to read real quotes from published authors.

Submit your manuscript here: https://www.dovepress.com/reports-in-medical-imaging-journal 